\title{
Ar-Ar and I-Xe Ages and the Thermal History of IAB Meteorites
}

\author{
Donald D. Bogard ${ }^{1}$, Daniel H. Garrison ${ }^{2}$, and Hiroshi Takeda ${ }^{3}$ \\ ${ }^{1}$ ARES, Code SR, NASA Johnson Space Center, Houston, TX 77058, U.S.A. \\ ${ }^{2}$ Lockheed Martin, Houston, TX 77058, U.S.A. \\ ${ }^{3}$ Research Inst., Chiba Inst. of Tech., 2-17-1 Tsudanuma, Narashino City, \\ Chiba 275-0016, Japan,
}

\begin{abstract}
Studies of several samples of the large Caddo County IAB iron meteorite reveal andesitic material, enriched in $\mathrm{Si}, \mathrm{Na}, \mathrm{Al}$ and $\mathrm{Ca}$, which is essentially unique among meteorites. This material is believed to have formed from a chondritic source by partial melting and to have further segregated by grain coarsening. Such an origin implies extended metamorphism of the IAB parent body. New ${ }^{39} \mathrm{Ar}-$

${ }^{40} \mathrm{Ar}$ ages for silicate from three different Caddo samples are consistent with a common age of 4.50-4.51 Gyr ago. Less well defined Ar-Ar degassing ages for inclusions from two other IABs, EET8333 and Udei Station, are $\sim 4.32 \mathrm{Gyr}$, whereas the age for Campo del Cielo varies considerably over $~ 3.23-4.56$ Gyr. New ${ }^{129} \mathrm{I}-{ }^{129} \mathrm{Xe}$ ages for Caddo County and EET8333 are 4557.9 $\pm 0.1 \mathrm{Myr}$ and 4557-4560 Myr, respectively, relative to an age of 4562.3 Myr for Shallowater. Considering all reported Ar-Ar degassing ages for IABs and related winonaites, the range is $4.32-4.53 \mathrm{Gyr}$, but several IABs give similar Ar ages of 4.50-4.52 Gyr. We interpret these older Ar ages to represent cooling after the time of last significant metamorphism on the parent body, and the younger ages to represent later ${ }^{40} \mathrm{Ar}$ diffusion loss. The older Ar-Ar ages for IABs are similar to $\mathrm{Sm}-\mathrm{Nd}$ and $\mathrm{Rb}-\mathrm{Sr}$ isochron ages reported in the literature for Caddo County. Considering the possibility that IAB parent body formation was followed by impact disruption, reassembly, and metamorphism (e.g., Benedix et al. 2000), the Ar-Ar ages and IAB cooling rates deduced from Ni concentration profiles in IAB metal (Herpfer et al., 1994) are consistent if the time of the post-assembly metamorphism was as late as $\sim 4.53 \mathrm{Gyr}$ ago. However, I-Xe ages reported for some IABs define much older ages of $\sim 4558-4566 \mathrm{Myr}$, which cannot easily be reconciled with the much younger Ar-Ar and Sm-Nd ages. An explanation for the difference in radiometric ages of IABs may reside in combinations of the following: a) I-Xe ages have very high closure temperatures and were not reset during metamorphism $\sim 4.53 \mathrm{Gyr}$ ago; b) a bias exists in the ${ }^{40} \mathrm{~K}$ decay constants which makes these Ar-Ar ages $\sim 30$ Myr too young; c) the reported Sm-Nd and $\mathrm{Rb}-\mathrm{Sr}$ ages for Caddo are in error by amounts equal to or exceeding their reported 2-sigma uncertainties; and d) about $30 \mathrm{Myr}$ after the initial heating that produced differentiation of Caddo silicate and mixing of silicate and metal, a mild metamorphism of the IAB parent body reset the Ar-Ar ages.
\end{abstract}




\section{INTRODUCTION}

$\mathrm{IAB}$ irons are one of a few types of iron meteorites which contain silicate inclusions and whose higher abundance of siderophile elements suggests that the metal was not solely formed as part of a differentiation sequence (Mittlefehldt et al. 1998). Inclusions in IABs show a wide range of types, including sulfide-, graphite-, and phosphate-rich, non-chondritic silicate, and those with more primitive chondritic silicate composition (Benedix et al., 2000). Winonaites are non-chondritic silicate meteorites, with much smaller metal contents, and are thought to derive from the same parent body as IAB irons (Benedix et al, 1998; Mittlefehldt et al. 1998). The oxygen isotopic composition for IABs and winonaites, however, are unlike other chondrite groups (Clayton and Mayeda, 1996). Formation models that have been proposed for IABs include parent body partial melting and fractional crystallization (Kracher, 1985) or incomplete differentiation (Takeda et al, 2000) due to internal heat sources, and impact-induced melting and mixing (Choi et al., 1995; Wasson and Kallemeyn, 2002). A chondritic parent was favored by several of these studies. Benedix et al. (2000) prefer a hybrid model whereby a chondritic parent experienced metamorphism, partial melting, and incomplete differentiation that produced metallic, sulfide-rich, and silicate partial melts. Benedix et al. (2000) suggest that the parent body may have reached interior temperatures of 1200-1400C and may have begun to differentiate. While the body was near its peak temperature, a large impact caused it to breakup. This was followed by reassembly, resulting in molten metal being mixed with near-surface silicate. Scott (2004) has suggested that such collisional breakup and reassembly of asteroidal bodies may have been common in the early solar system.

Coarse-grained gabbroic material rich in plagioclase and diopside (Di) occurs in the Caddo County IAB iron meteorite (Takeda et al., 2000) and represents a new type of chemically differentiated, extra-terrestrial silicate material. Because of the high abundance of Na-rich plagioclase (albite, Ab), the bulk composition $\left(\mathrm{SiO}_{2}=59 \mathrm{wt} \%\right)$ is within the field of andesites. Similar materials were found in silicate inclusions in many IIE irons (Takeda et al., 2003). The andesitic materials can be a general partial melt product of the chondritic source materials. Andesitic materials of this type previously studied are surrounded by orthopyroxene (Opx) and olivine, and it has been difficult to estimate their bulk compositions. A new Caddo sample described in this work contains a large inclusion of mainly Di and $\mathrm{Ab}$ surrounded by metal. This sample will provide us with further information on formation mechanisms by inhomogeneous segregation of partial melts from chondritic sources.

An understanding the thermal history of IAB meteorites requires accurate determination of their radiometric ages, and several radiometric ages for $\mathrm{IAB}$ meteorites have been reported (and are summarized later). Most reported ${ }^{129} \mathrm{I}-{ }^{129} \mathrm{Xe}$ ages are $>4.56 \mathrm{Gyr}$ and a few are $\geq 4.567 \mathrm{Gyr}$. The oldest I$\mathrm{Xe}$ ages are troubling because they equal or exceed the $4.567 \mathrm{Gyr} \mathrm{Pb}-\mathrm{Pb}$ age of $\mathrm{Ca}$, Al-rich inclusions in primitive meteorites, which are thought to be the earliest condensates in the solar system (Amelin et al., 2002). In contrast to the I-Xe ages, ${ }^{39} \mathrm{Ar}-{ }^{40} \mathrm{Ar}$ ages of silicate from several IABs and the Sm-Nd age of one IAB meteorite appear significantly younger at $~ 4.53-4.43 \mathrm{Gyr}$. In addition, Herpfer et al. (1994) used $\mathrm{Ni}$ concentration profiles in metal to determine cooling rates of $\sim 25-70{ }^{\circ} \mathrm{C} / \mathrm{Myr}$ for eight IAB meteorites, suggesting that an extended cooling history of the IAB parent body might result in different expected ages for different chronometer systems. Because of the spread in apparent radiometric ages, the evidence for relatively slow cooling rates, and the complex history of the IAB body preferred by 
Benedix et al. (2000), we undertook a new Ar-Ar and I-Xe study of some IAB silicates.

\section{EXPERIMENTAL}

\section{Samples:}

A general description of IAB iron meteorites and brief comments on some of the meteorites studied here are given in Mittlefehldt et al. (1998). Caddo County sample \#5 was taken from a portion of the original slice that yielded the gabbroic material previously studied by Takeda et al (2000). However, sample \#5 is not gabbroic, but represents a more winonaite-like composition thought to be residual from the partial differentiation experienced by Caddo. The material was coarsely crushed and a magnetic fraction was removed with a hand magnet. A split of the non-magnetic portion was treated with an agent to remove abundant Fe weathering products. The resulting material consisted of $\sim 60 \%$ clear grains, free of Fe staining, and $11 \mathrm{mg}$ of this was irradiated for Ar-Ar.

Caddo County sample 027 was received as a rod of mostly metal $\sim 2 x 1 \times 0.7 \mathrm{~cm}(2.7 \mathrm{~g})$ containing one silicate inclusion exposed near its center. This inclusion was extracted and part of it was cleaned to remove abundant $\mathrm{Fe}$ weathering products and then was coarsely crushed. The more magnetic fraction was removed with a hand magnet and the non-magnetic fraction was sieved. The 75-200 $\mu \mathrm{m}$ fraction consisted of mixed silicate grains free of Fe stain, and $48 \mathrm{mg}$ of this was taken for irradiation.

Caddo County sample EH was also received as a rod of mostly metal, which contained several possibly interconnected inclusions. Several inclusions were removed and combined. A plagioclaseenriched phase was prepared from a $75-250 \mu \mathrm{m}$ size fraction by magnetic separation followed by hand picking of white to colorless grains (Y. Liu, pers. comm.).

Both Caddo sample 027 and sample EH were obtained from the Planetary Materials Database Collections of Univ. of Tokyo. Several grains of the 027 material described above were mounted in a PTS. A PTS $(9.5 \times 7.4 \mathrm{~mm}$ in size), made from a separate sample of 027 , consists mainly of silicates with numerous metal veins. A PTS prepared from the EH sample contained one large silicate inclusion $0.8 \times 0.7 \mathrm{~cm}$ in size and encapsulated in metal.

A 2.15 g sample of silicate inclusion \#2 from Campo del Cielo (\#5615) was provided by the USNM, and is the same inclusion studied by Bild (1977). Several whole rock chips weighing $46 \mathrm{mg}$ were irradiated for Ar-Ar.

Metal bars of four IAB meteorites, not previously studied for chronology, were provided by the U.S. National History Museum. Each of these contained small veins and/or inclusions of mixed silicate, graphite, and probably troilite. A $19 \mathrm{~g}$ piece of Kendall County contained $\sim 5-10 \%$ of black inclusions that appeared to be mostly graphite and troilite. This piece was broken and a $7.8 \mathrm{~g}$ piece was dissolved in cold $1 \mathrm{~N}-\mathrm{HNO}_{3}$ for 6 days. Approximately half of the metal dissolved and released the inclusions. The residue of graphite and silicate was sieved into $>200,125-200$, and $<125 \mu \mathrm{m}$ fractions with a total weight of $\sim 0.6 \mathrm{~g}$. Because the finest fraction $(0.29 \mathrm{~g})$ appeared to contain the most silicates, heavy liquids were used to produce a $2.44-2.85 \mathrm{gm} / \mathrm{cc}$ density fraction $(\sim 0.0068 \mathrm{~g})$, which was $\sim 2 / 3$ white grains, and a $>2.85 \mathrm{gm} / \mathrm{cc}$ density fraction $(\sim 0.0212 \mathrm{~g})$, which was $\sim 3 / 4$ white grains. For Ar-Ar analysis, we combined these two density fractions and irradiated $0.028 \mathrm{~g}$.

A $5.5 \mathrm{~g}$ piece of EET 83333,5 contained a mostly silicate inclusion, which was removed, crushed, and sieved. For Ar-Ar analysis we used $0.027 \mathrm{~g}$ of the $<125 \mu \mathrm{m}$ fraction, and for I-Xe analysis we used $0.0616 \mathrm{~g}$ of the $125-200 \mu \mathrm{m}$ fraction. A $81 \mathrm{~g}$ piece of Udei Station was mostly metal 
with $\sim 5 \%$ dark/black inclusions of troilite or graphite, with no obvious silicate grains present. We removed $\sim 1 \mathrm{~g}$ of inclusions, sieved these through $200 \mu \mathrm{m}$, and used a hand magnet to remove $\sim 1 / 2$ of that material with strong magnetic affinity. The remaining material showed a weak magnetic response and consisted of $\sim 50 \%$ silicate clear/amber grains and $\sim 50 \%$ opaque material, possibly troilite. For ArAr analysis we used $0.044 \mathrm{~g}$ of this material. For I-Xe analysis we used the remaining $0.033 \mathrm{~g}$ of this $<200 \mu \mathrm{m}$, low-magnetic material, plus $0.047 \mathrm{~g}$ of $>200 \mathrm{um}$, low-magnetic fraction, for a total mass of $0.080 \mathrm{~g}$. A $5.5 \mathrm{~g}$ piece of Linwood was broken into a few pieces, but no silicates were apparent. No analyses were made of this meteorite.

\section{Methods:}

The PTSs from Caddo samples EH and 027 were studied by an optical microscope and an electron probe micro-analyzer (EPMA) at Ocean Res. Inst. (ORI) of Univ. of Tokyo. The Area Analysis technique of the JEOL 8900 EPMA was applied to obtain elemental distribution maps of Na, $\mathrm{Si}, \mathrm{Ca}, \mathrm{Fe}, \mathrm{K}, \mathrm{Mg}, \mathrm{Al}, \mathrm{Cr}, \mathrm{Ti}, \mathrm{S}$ and $\mathrm{Ni}$ by the courtesy of Dr. T. Ishii and Mayumi Otsuki of ORI. A mineral distributions map of each PTS was constructed by combining the elemental maps of $\mathrm{Ca}, \mathrm{Na}$, $\mathrm{Mg}$, Si. Chemical compositions of minerals were obtained with EPMA, JEOL JCXA-733 at ORI with WDS. The modal abundance (vol. \%) of silicate minerals was derived from the mineral distribution map. Bulk chemical compositions (Table 1) were calculated from the modal abundance and chemical compositions of each silicates.

Neutron irradiations for Ar-Ar and I-Xe dating were made at the University of Missouri Research Reactor. Caddo County \#5, Caddo Co. EH, and Campo del Cielo were included in irradiation 02B (average irradiation constant, J=0.022). Caddo Co. 027, EET8333, Udei Station, and Kendall County were included in irradiation 03A (average $\mathrm{J}=0.025$ ). Each irradiation included at least 7 samples of hornblende NL25 as irradiation flux monitors of known age (Bogard et al, 1995). A 92 mg whole rock sample of the gabbro-enriched portion of Caddo Co. sample 2B (Takeda et al., 2000) was packaged between two whole rock samples of the Shallowater aubrite and included in irradiation 02B. Samples of EET833 and Udei Station were packaged between two samples of Shallowater and included in irradiation 03A. Each irradiated sample was dropped into a deep Ta crucible equipped with an intrinsic W-Re thermocouple and heated stepwise by means of a solid-state, induction generator, whose coil is positioned around the outside of the vacuum system. Extraction temperatures are readily controlled and were held constant to within $\pm 5^{\circ} \mathrm{C}$ for the usual 30 minute heating times. In the case of Ar-Ar dated samples, the gas released at each extraction temperature was purified on active metal getters and the isotopic composition of the Ar was measured with a mass spectrometer. In the case of IXe dated samples, the Xe released was separated from lighter noble gases on chilled charcoal, gettered, and its isotopic composition measured on a mass spectrometer. Ar isotopic data were not measured for these samples.

Argon isotopic data were corrected for instrument mass discrimination, system blanks, radioactive decay, and isotopic interferences produced in the reactor. Reasonable uncertainties in these corrections were compounded with one sigma uncertainties in isotopic ratio measurements in order to calculate uncertainties in the Ar-Ar age for each extraction. These are the uncertainties shown in the presented Ar-Ar age spectra. Where we report an overall Ar-Ar plateau age obtained from several extractions, or an isochron age, we combine the uncertainty assigned to that age with the uncertainty in 
determination of the J-value for that sample. Reported Ar-Ar ages do not consider the uncertainty in the age of the NL25 monitor, which is estimated at less than $\pm 0.5 \%$ based on absolute measurements (Bogard et al., 1995) and on comparisons with other Ar-Ar age monitors (Renne, 2000). Xenon isotopic data were corrected for mass discrimination and system blanks. The conversion of measured ${ }^{129} \mathrm{Xe} /{ }^{128} \mathrm{Xe}$ ratios into an I-Xe age is described in more detail below.

\section{PETROLOGICAL PERSPECTIVE}

\section{Caddo PTS Observations}

The silicate inclusion in PTS-EH is coarse-grained and composed of one large semi-euhedral diopside (Di) $2.7 \times 1.4 \mathrm{~mm}$ in size with one side attached to metal, and smaller granular ones set in albite $(\mathrm{Ab})$, and minor metal and troilite (Fig. 1). The diopside grain is an unshocked, clear crystal, but has opaque mineral inclusions aligned along a curved line. Irregular shaped orthopyroxene (Opx) inclusions are also present. The chemical composition (Table 1) of $\mathrm{Di}\left(\mathrm{Ca}_{45} \mathrm{Mg}_{52} \mathrm{Fe}_{3}\right)$ and $\mathrm{Ab}\left(\mathrm{Or}_{3} \mathrm{Ab}_{80-84} \mathrm{An}_{12-16}\right)$ are the same as those reported previously for Caddo \#3A (Takeda et al., 2000). Modal abundance of minerals obtained from the mineral distribution map are: diopside $53.2 \mathrm{vol}$. \%, albite $45.6 \%$, Orthopyroxene (Opx) 1.2\%, olivine $<0.02 \%$.

Large $\mathrm{Ab}$ grains up to $1.4 \times 0.7 \mathrm{~mm}$ in size showing twin lamellae poikilitically include small ellipsoidal Opx $\left(\mathrm{Ca}_{2} \mathrm{Mg}_{92} \mathrm{Fe}_{6}\right)$, or diopside, or both. Opx reaches up to $0.18 \times 0.07 \mathrm{~mm}$ in size. Only one olivine grain (Fo98), $0.15 \times 0.10 \mathrm{~mm}$ in size, was found. Minor, irregular Opx grains distribute as dusty aggregates or thin film-like veins. Several grains of alabandite $\left(\mathrm{Mn}_{0.93} \mathrm{Fe}_{0.06}\right) \mathrm{S}$ up to $0.16 \times 0.10 \mathrm{~mm}$ are found in troilite mantling the silicate inclusion.

PTS-027 does not contain large metal portions. A silicate inclusion $9.5 \times 7.4 \mathrm{~mm}$ in size is penetrated by networks of metal and troilite (Fig. 2). A predominately large, subrounded diopside crystal and twinned albite constitute major portions of PTS-027. Small oval shaped olivine and mafic silicate crystals are poikilitically enclosed in the albite. Grain boundaries of small subrounded grains of olivine, orthopyroxene, diopside and albite surrounding the large crystals are penetrated by veins of metal and troilite.

One moderate Opx crystal is present adjacent to these two large minerals. The Opx crystal is clear and free from inclusions and shows simultaneous extinction, but short linear parallel arrays of dislocation-like segment decorated by fine opaque minerals are distributed along slightly curved plane (Fig. 3). This texture is similar to tilt-boundaries observed in olivine grains in pallasite and Opx in diogenite (Mori and Takeda, 1981).

In the fine-grained areas of silicate minerals, part of opaque veins previously at the grain boundary are left in a larger grown crystal. The presence of such textures and a few predominantly large crystals in an inclusion, suggests that grain coarsening of diopside and albite is another important mechanism to produce silicate inclusions in the IAB parent body.

\section{Implications for Chondritic Partial Melts and Isotopic Ages:}

Small crystals surrounding a few large crystals in PTSs of Caddo County can be remnants of the winonaite-like materials, which did not grow larger by the grain coarsening mechanism. The growth of a large crystal at the expense of such small ones will lower the free energy of the entire system. 
Transportation of partial melts from the chondritic source regions through grain boundaries may be promoted by this grain coarsening mechanism in addition to the "Marangoni convection" previously proposed (Takeda et al., 2000).

The presence of curved metal veins and small opaque grains arranged along a curved line in a few large crystals suggests that the vein may be a remnant of a metal vein penetrated into the preexisting smaller crystal and that opaque grains at previous grain boundaries might have been included during the slow crystal growth process of the grain coarsening. The arrays of dislocation-like texture in a clear large single crystal of Opx suggest also similar process. The dislocation arrays may be former grain boundaries or may have produced by a shock event. These textures cannot be produced by a break-up and reassemble model. After formation of a planetesimal and first partial melting and crystal growth, which is recorded in the old I-Xe age (discussed later), a meteoroid impact disturbed the system. Then, a small degree of partial melting and migration of partial melt further promoted the growth of a few large crystals of diopside and albite. The final cooling of this event is recorded in the younger Ar-Ar age (discussed later).

Discovery of an andesitic silicate inclusion in Caddo with less than 2\% of Opx and olivine supports the previous proposal (Takeda et al., 2000) that melt segregated from chondritic source materials is unlike eucrites, and has an andesitic composition. The presence of the large Di biases the bulk composition, but discussion of the REE abundances (Takeda H. et al., 2001) estimated from the previous modal abundance is still supported. The presence of albite contributed to precise determination of the Ar-Ar age. Extraterrestrial andesites have been proposed for Mars by the Pathfinder team (McSween, 2002) without a mineralogical basis, but the material described in this paper is the first reported andesitic asteroidal material. The textures, mineralogy (Takeda et al., 2000) and REE data (Takeda et al., 2001) suggest that the andesitic materials were not formed by Earth-like mechanisms, but formed very early by inhomogeneous segregation of partial melts and the grain coarsening mechanism from chondritic source materials.

\section{${ }^{39} \mathrm{Ar}-{ }^{40} \mathrm{Ar}$ AGES}

\section{Caddo County}

$\mathrm{The}^{39} \mathrm{Ar}-{ }^{40} \mathrm{Ar}$ age spectra and $\mathrm{K} / \mathrm{Ca}$ ratios as a function of cumulative release of ${ }^{39} \mathrm{Ar}$ are shown in Fig 4 for Caddo County samples \#5, \#027, and \#EH. Changes in the K/Ca ratios and in the rate of release of ${ }^{39} \mathrm{Ar}$ with extraction temperature indicate that $\mathrm{K}$ in each sample resided in more than one diffusion domain. However, for each sample the Ar-Ar ages are relatively flat throughout most of the age spectrum and give a well-defined plateau. Each sample released terrestrial Ar in the first few extractions and a non-cosmogenic component of trapped meteoritic ${ }^{36} \mathrm{Ar}$ in the high temperature extractions. For examining Ar isotopic data in isochrons, we applied corrections for cosmogenic ${ }^{36} \mathrm{Ar}$ using the observed minimum in the ${ }^{36} \mathrm{Ar} /{ }^{37} \mathrm{Ar}$ ratio.

For Caddo \#5, 15 extractions releasing 94\% of the total ${ }^{39} \mathrm{Ar}$ define a plateau age of 4.507 \pm 0.013 Gyr. These same extractions define a very precise isochron $\left(\mathrm{R}^{2}=0.99999\right.$; corrected for cosmogenic ${ }^{36} \mathrm{Ar}$ ) of ${ }^{40} \mathrm{Ar} /{ }^{36} \mathrm{Ar}$ versus ${ }^{39} \mathrm{Ar} /{ }^{36} \mathrm{Ar}$. The slope of this isochron gives an age of 4.504 $\pm 0.012 \mathrm{Gyr}$ (including \pm in J). The isochron ${ }^{40} \mathrm{Ar} /{ }^{36} \mathrm{Ar}$ intercept of $10 \pm 34$ indicates that trapped ${ }^{40} \mathrm{Ar}$ is not present. For Caddo Co. $\# 027,25$ extractions $\left(700-1350^{\circ} \mathrm{C}\right)$ releasing $96.5 \%$ of the total ${ }^{39} \mathrm{Ar}$ define a plateau age of $4.506 \pm 0.010$ Gyr. The ages for 11 extractions over $\sim 16-57 \%$ of the ${ }^{39} \mathrm{Ar}$ release 
suggest a small systematic increase in age ( $10 \mathrm{Myr})$, but this increase may not be real. The Caddo 027 age for 16 extractions releasing $56-99 \%$ of the ${ }^{39} \mathrm{Ar}$ is very similar at $4.507 \pm 0.010 \mathrm{Gyr}$. These same 25 extractions define a very precise isochron $\left(R^{2}=0.999999\right.$; corrected for cosmogenic $\left.{ }^{36} \mathrm{Ar}\right)$ whose slope gives an age of $4.510 \pm 0.008 \mathrm{Gyr}$ and whose ${ }^{40} \mathrm{Ar} /{ }^{36} \mathrm{Ar}$ intercept is $-33 \pm 15$. For Caddo \#EH, 32 extractions releasing $>99 \%$ of the total ${ }^{39} \mathrm{Ar}$ give an age of $4.48 \pm 0.03 \mathrm{Gyr}$, and 20 extractions releasing over $21-100 \%$ of the ${ }^{39} \mathrm{Ar}$ define a plateau age of $4.489 \pm 0.023 \mathrm{Gyr}$. The isochron age $\left(\mathrm{R}^{2}=0.99998\right.$; corrected for cosmogenic ${ }^{36} \mathrm{Ar}$ ) is $4.483 \pm 0.012 \mathrm{Gyr}$. The ${ }^{40} \mathrm{Ar} /{ }^{36} \mathrm{Ar}$ intercept of $185 \pm 83$ suggests some trapped ${ }^{40} \mathrm{Ar}$ occurs in this sample. Although the age for EH appears slightly younger than the ages for \#5 and \#027, its age is indistinguishable within uncertainties. The analysis of the EH sample experienced some organic contamination and thus larger isotopic measurement uncertainties, especially at lower extraction temperatures. This may have contributed slightly to the mass 39 signal and artificially lowered the age. The Caddo data indicate the K-Ar closure time during cooling from IAB parent body metamorphism to have been $\sim 4.507$ Gyr ago.

\section{EET8333, Udei Station, Campo del Cielo, and Kendall County}

The ${ }^{39} \mathrm{Ar}-{ }^{40} \mathrm{Ar}$ age spectra and $\mathrm{K} / \mathrm{Ca}$ ratios as a function of cumulative release of ${ }^{39} \mathrm{Ar}$ are shown in Fig. 5 for inclusions from EET-83333, Udei Station, Campo del Cielo, and Kendall County. Lower temperature data for EET83333 show some ${ }^{40} \mathrm{Ar}$ diffusion loss, possibly from terrestrial weathering. The small decrease in age at $>92 \%{ }^{39} \mathrm{Ar}$ release for EET 83333 is associated with a substantial decrease in the $\mathrm{K} / \mathrm{Ca}$ ratio, probably caused by the onset of pyroxene degassing. These younger ages may have been produced by the release of ${ }^{39} \mathrm{Ar}$ that recoiled, during neutron irradiation, from the high-K phase that degasses at very low extraction temperatures into pyroxene grain surfaces. Twelve extractions releasing between $34 \%$ and $92 \%$ of the ${ }^{39} \mathrm{Ar}$ give an age of $4.306 \pm 0.014 \mathrm{Gyr}$. Eight extractions releasing 54-92\% of the ${ }^{39} \mathrm{Ar}$ define an age of $4.313 \pm 0.011 \mathrm{Gyr}$. The two oldest ages $\left(77-92 \%{ }^{39} \mathrm{Ar}\right.$ release) have a value of $4.32 \pm 0.01 \mathrm{Gyr}$. Because over $34-92 \%{ }^{39} \mathrm{Ar}$ release the ages show a slight upward trend, possibly suggesting small amounts of ${ }^{40} \mathrm{Ar}$ diffusion loss, we suggest that an age of 4.32 \pm 0.02 Gyr represents the last time that the K-Ar age of EET83333 was totally reset by metamorphic degassing.

The Ar-Ar age spectrum for Udei Station reveals an even greater amount of diffusive loss of ${ }^{40} \mathrm{Ar}$, and the data do not define an age plateau. Eight extractions releasing $80-98 \%$ of the ${ }^{39} \mathrm{Ar}$ give an average age of $4.29 \mathrm{Gyr}$, and the highest age shown is $4.31 \mathrm{Gyr}$. Complete metamorphic resetting of the K-Ar age for Udei Station may have occurred at about the same time as was the case for EET8333.

The Ar-Ar age spectrum for Campo del Cielo is complex. Higher ${ }^{36} \mathrm{Ar} /{ }^{37} \mathrm{Ar}$ ratios and older apparent ages in the first few extractions may be due to the release of terrestrial ${ }^{40} \mathrm{Ar}$. An isochron plot of ${ }^{40} \mathrm{Ar} /{ }^{36} \mathrm{Ar}$ versus ${ }^{39} \mathrm{Ar} /{ }^{36} \mathrm{Ar}$ for those extractions releasing $0-35 \%$ of the ${ }^{39} \mathrm{Ar}\left(\mathrm{R}^{2}=0.99998\right.$; corrected for cosmogenic ${ }^{36} \mathrm{Ar}$ ) gives an age of $3.340 \pm 0.007 \mathrm{Gyr}$ and $\mathrm{a}{ }^{40} \mathrm{Ar} /{ }^{36} \mathrm{Ar}$ intercept of $193 \pm 19$. It is not clear if this young age represents a discreet heating event. Five extractions releasing $67-83 \%$ of the ${ }^{39} \mathrm{Ar}$ suggest a quasi-plateau with an average age of $4.433 \pm 0.011 \mathrm{Gyr}$. The isochron for these data $\left(\mathrm{R}^{2}\right.$ $=0.99995$; corrected for cosmogenic ${ }^{36} \mathrm{Ar}$ ) gives an age of $4.432 \pm 0.009 \mathrm{Gyr}$ and a ${ }^{40} \mathrm{Ar} /{ }^{36} \mathrm{Ar}$ intercept of $0.1 \pm 2$. The last five extractions releasing $83-100 \%$ of the ${ }^{39} \mathrm{Ar}$ show an increase in age up to values of $\sim 4.56$ Gyr. Substantial amounts of ${ }^{40} \mathrm{Ar}$ and ${ }^{39} \mathrm{Ar}$ were released by four of these extractions, and we do not believe these older ages were caused by improper corrections for system blanks. An isochron plot of 
these five extractions $\left(R^{2}=0.99996\right.$; corrected for cosmogenic ${ }^{36} \mathrm{Ar}$ ) gives an age of $4.549 \pm 0.009 \mathrm{Gyr}$ and $\mathrm{a}^{40} \mathrm{Ar} /{ }^{36} \mathrm{Ar}$ intercept of $0.19 \pm 0.16$. Extractions showing these oldest ages have lower $\mathrm{K} / \mathrm{Ca}$ ratios, and it is possible that this low $\mathrm{K} / \mathrm{Ca}$ phase contained excess ${ }^{40} \mathrm{Ar}$ redistributed during metamorphism. Thus, the Ar-Ar age spectrum of Campo del Cielo is suggestive of material 4.55 Gyr old that experienced a strong heating event at $\sim 4.43 \mathrm{Gyr}$ and possibly at $\sim 3.34 \mathrm{Gyr}$.

Our sample of Kendall County contained very low K ( 29 ppm), and the individual Ar-Ar ages have large uncertainties. Argon degassed from two phases whose K/Ca ratios differ by a factor of 100 . The lower temperature phase has lost much of its ${ }^{40} \mathrm{Ar}$. The higher temperature phase suggests an age of $\geq 4.5 \mathrm{Gyr}$, and 10 extractions releasing $62-100 \%$ of the ${ }^{39} \mathrm{Ar}$ give an average age of $4.64 \pm 0.12$. Argon blank corrections applied to those data yielding the old ages were several percent, and corrections to ${ }^{39} \mathrm{Ar}$ for reactor interferences were $>50 \%$ for some extractions. An isochron plot of these same 10 extractions $\left(R^{2}=0.998\right)$ gives an age of $4.47 \pm 0.03 \mathrm{Gyr}$ and $\mathrm{a}^{40} \mathrm{Ar} /{ }^{36} \mathrm{Ar}$ intercept of $2.7 \pm 0.9$. Thus, the high apparent ages may be the result of redistribution of some radiogenic ${ }^{40} \mathrm{Ar}$ during metamorphism. Although the Ar-Ar metamorphic age for Kendall County is not well defined, it is consistent with the age range shown by other IAB meteorites.

\section{I-Xe AGES}

Radiogenic ${ }^{129} \mathrm{Xe}^{*}$ accumulated in meteorites during the first $\sim 10^{8}$ years as a consequence of the decay of the now-extinct radionuclide ${ }^{129} \mathrm{I}$ (half-life $\sim 15.7 \mathrm{Myr}$ ). Neutron irradiation in a reactor converts a portion of the stable ${ }^{127} \mathrm{I}$ to ${ }^{128} \mathrm{Xe}^{*}$, part of which will reside in the same lattice sites as the radiogenic ${ }^{129} \mathrm{Xe}^{*}$. To determine an I-Xe age, the measured ${ }^{129} \mathrm{Xe}^{* / 28} \mathrm{Xe}^{*}$ ratio in a given sample is compared against the absolute age of another sample determined from an absolute chronometer. Nichols et al. (1994) measured the ${ }^{129} \mathrm{Xe}^{* / 28} \mathrm{Xe}^{*}$ ratio in phosphate of the Acapulco primitive achondrite, for which $\mathrm{Pb}-\mathrm{Pb}$ dating yielded an absolute age of $4.557 \pm 0.002 \mathrm{Gyr}$ (Göpel, 1992). However, workers today prefer to use the Shallowater aubrite as an I-Xe dating standard, because this is an igneous meteorite whose major halogen-bearing phase is encapsulated in enstatite (McCoy et al., $1995)$ and thus is protected against secondary age resetting. Radiogenic ${ }^{129} \mathrm{Xe}^{*}$ also is released from Shallowater at relatively high temperatures and thus is more easily resolved from other Xe components. Brazzle et al. (1999) reported the absolute I-Xe age of Shallowater and the Bjurböle chondrite, used extensively in earlier work as an age standard, each to be $4.566 \pm 0.002$ Gyr. Later work on chondrules from chondrites cast some doubt on this absolute I-Xe age calibration (Pravdivtseva et al., 2002). More recently, I-Xe ages, ${ }^{53} \mathrm{Mn}-{ }^{53} \mathrm{Cr}$ ages, and $\mathrm{Pb}-\mathrm{Pb}$ ages in several meteorites have been compared to each other and to the absolute $\mathrm{Pb}-\mathrm{Pb}$ age of the LEW86010 angrite. With this calibration the I-Xe age of Shallowater has been reported as $\sim 4564 \mathrm{Myr}$ (Busfield et al., 2004) and 4562.3 $\pm 0.4 \mathrm{Myr}$ (Gilmour et al., 2004). In this paper we adopt the I-Xe ages of both Shallowater and Bjurböle to be $4562.3 \mathrm{Myr}$.

\section{Caddo County}

For stepwise temperature extractions of the irradiated Caddo County sample, Xe isotopes 128, 129 , and 132 all display prominent peaks in concentration over the temperature range of $1100-1300^{\circ} \mathrm{C}$, and the ${ }^{128} \mathrm{Xe} /{ }^{132} \mathrm{Xe}$ and ${ }^{129} \mathrm{Xe} /{ }^{132} \mathrm{Xe}$ ratios show strong maxima in the $1330^{\circ} \mathrm{C}$ extraction. Figure 6a is an isochron plot of measured ${ }^{129} \mathrm{Xe} /{ }^{132} \mathrm{Xe}$ ratios against ${ }^{128} \mathrm{Xe} /{ }^{132} \mathrm{Xe}$ ratios. Eight extractions over the 
temperature range $950-1330^{\circ} \mathrm{C}$ released $94 \%$ of the total ${ }^{128} \mathrm{Xe}$ and define a linear relationship having a slope of $0.3909 \pm 0.0010(2 \sigma)$ and an intercept on the ${ }^{129} \mathrm{Xe} /{ }^{132} \mathrm{Xe}$ axis of $1.05 \pm 0.07$. Although the $1415^{\circ} \mathrm{C}$ extraction also falls close to this isochron, its residual from the isochron is larger than those for the other points, and it is not included in defining the isochron. The $500-850^{\circ} \mathrm{C}$ extractions, releasing $\sim 5 \%$ of the ${ }^{128} \mathrm{Xe}$, plot below this I-Xe isochron, indicating that they have lost part of their ${ }^{129} \mathrm{Xe}^{*}$ by diffusion at some point during the meteorite's history.

We also calculated the best-fit isochron using the formulism given by Williamson (1968), which weighs each isotopic ratio by its individual uncertainty and which commonly is utilized with other radiometric dating techniques. For eight extractions this gives a slope and intercept of $0.3874 \pm 0.0047$ $(2 \sigma)$ and $1.17 \pm 0.06$, respectively. If we omit the two points with the most radiogenic Xe (highest ${ }^{128} \mathrm{Xe} /{ }^{132} \mathrm{Xe}$ ), which dominate the slope, the Williamson slope and intercept remain nearly unchanged at $0.3869 \pm 0.0050$ and $1.18 \pm 0.06$, respectively. The Williamson fit gives a trapped ${ }^{129} \mathrm{Xe} /{ }^{132} \mathrm{Xe}$ ratio slightly higher than the ratio of $\sim 1.04$ typically observed in meteorites. The higher trapped ${ }^{129} \mathrm{Xe} /{ }^{132} \mathrm{Xe}$ may suggest some redistribution of ${ }^{129} \mathrm{Xe}^{*}$ during metamorphism (Gilmour et al., 2001), which is also suggested by the detailed shape of the ${ }^{128} \mathrm{I}-{ }^{129} \mathrm{Xe}$ age spectrum discussed below. For Caddo Co. we adopt an isochron slope of $0.3874 \pm 0.0047$.

The Caddo Xe data plotted in Fig. 6a have been corrected for spallation Xe in the following manner. We assumed that the trapped Xe isotopic composition is terrestrial for the first three temperature extractions and is like carbonaceous chondrites (Pepin, 1991) at higher temperatures. However, this correction is insensitive to the trapped component assumed. We used the measured ${ }^{126} \mathrm{Xe} /{ }^{136} \mathrm{Xe}$ ratios and the spallation Xe spectra summarized by Bogard et al. (1971) to calculate abundances of cosmogenic ${ }^{128} \mathrm{Xe},{ }^{129} \mathrm{Xe}$, and ${ }^{132} \mathrm{Xe}$. For all temperature extractions except two $\left(500^{\circ}\right.$ and $750^{\circ} \mathrm{C}$ ) the corrections to the ${ }^{129} \mathrm{Xe} /{ }^{128} \mathrm{Xe}$ ratios were $\leq 0.2 \%$ and have a negligible effect on the slope and intercept of the isochron.

Xenon produced by neutron-induced fission of ${ }^{235} \mathrm{U}$ in our irradiated Caddo sample greatly dominates over that produced by spontaneous fission of U-Th. Most of this fission Xe was released in the $645-850^{\circ} \mathrm{C}$ extractions, which are not used in deriving an I-Xe age. Because ${ }^{132} \mathrm{Xe}$ is used to normalize the data plotted in Fig. 6, any applied correction for fission ${ }^{132} \mathrm{Xe}$ shifts the eight points defining the ${ }^{129} \mathrm{Xe}^{* / 128} \mathrm{Xe}^{*}$ isochron along the isochron line without changing its slope. Even if we were to assume a fission ${ }^{129} \mathrm{Xe} /{ }^{136} \mathrm{Xe}$ ratio as high as 0.1 , corrections to the $950-1415^{\circ} \mathrm{C}$ extractions would be all $<0.2 \%$.

\section{Shallowater}

The release of ${ }^{129} \mathrm{Xe}$ and ${ }^{128} \mathrm{Xe}$ from all four Shallowater samples analyzed peaked sharply at $\sim 1100^{\circ} \mathrm{C}$, but trapped ${ }^{132} \mathrm{Xe}$ shows a much broader release with temperature (c.f., Hohenberg, 1967). The I concentration of Shallowater is only one-quarter that of our Caddo Co sample. We applied very small corrections for spallation Xe to those Shallowater extractions used to construct an isochron, in a manner analogous to that for Caddo. These spallation corrections produced very little change in the derived ${ }^{129} \mathrm{Xe}^{*} /{ }^{128} \mathrm{Xe} *$ ratio. Fission $\mathrm{Xe}$ primarily was released from Shallowater at temperatures of $\sim 700^{\circ} \mathrm{C}$, and we did not apply a correction for fission Xe to the isochron data.

Figure $6 \mathrm{~b}$ plots ${ }^{129} \mathrm{Xe} /{ }^{132} \mathrm{Xe}$ ratios against ${ }^{128} \mathrm{Xe} /{ }^{132} \mathrm{Xe}$ ratios for the $>1050{ }^{\circ} \mathrm{C}$ temperature extractions of the two Shallowater samples (1-02 and 2-02) that bracketed the Caddo sample during 
neutron irradiation 02B. The highest temperature extraction for sample 1-02 is not included, because it released small amounts of Xe and plots slightly off the isochron. Data for $<1050^{\circ} \mathrm{C}$ extractions all plot below the isochron and indicate that Shallowater lost part of its ${ }^{129} \mathrm{Xe}$ by diffusion at some point in the meteorite's history. Any gradient in neutron flux along the sample vial would be averaged out by taking the average ${ }^{129} \mathrm{Xe} /{ }^{128} \mathrm{Xe}$ isochron for these 10 data points, which have a ${ }^{129} \mathrm{Xe} /{ }^{128} \mathrm{Xe}$ slope of 0.4790 $\pm 0.0024(2 \sigma)$ and $a^{129} \mathrm{Xe} /{ }^{132} \mathrm{Xe}$ intercept of $0.894 \pm 0.023$. The isochron is defined by $73 \%$ and $84 \%$ of the total ${ }^{128} \mathrm{Xe}$ released from Shallowater 1-02 and 2-02, respectively. Using the Williamson (1969) formulism to weigh each isotopic ratio by its individual uncertainty, the slope of this Shallowater isochron is $0.4718 \pm 0.0092$, the value we adopt, and the ${ }^{129} \mathrm{Xe} /{ }^{132} \mathrm{Xe}$ intercept is $0.94 \pm 0.05$.

Figure $6 \mathrm{~b}$ also plots ${ }^{129} \mathrm{Xe} /{ }^{132} \mathrm{Xe}$ ratios against ${ }^{128} \mathrm{Xe} /{ }^{132} \mathrm{Xe}$ ratios for five stepwise temperature extractions between $1050^{\circ} \mathrm{C}$ and $1350^{\circ} \mathrm{C}$ for each of the two Shallowater samples, (1-03 and 2-03) positioned on either side of EET8333 and Udei Station in separate irradiation \#03. These ten extractions released $60 \%$ and $83 \%$, respectively, of the total ${ }^{128} \mathrm{Xe}$. Note that the ${ }^{129} \mathrm{Xe} /{ }^{132} \mathrm{Xe}$ scale for these data in Fig. $6 \mathrm{~b}$ is offset from the scale for the two 02 Shallowater samples. These ten extractions give a combined ${ }^{129} \mathrm{Xe}^{* / 128} \mathrm{Xe}^{*}$ slope of $0.4024 \pm 0.0024$ and an intercept of $0.91 \pm 0.05$. Using the Williamson (1969) formulism to weigh each isotopic ratio by its individual uncertainty, the slope of this Shallowater isochron is $0.3982 \pm 0.0095$, the value we adopt, and the ${ }^{129} \mathrm{Xe} /{ }^{132} \mathrm{Xe}$ intercept is 0.93 \pm 0.10 .

As an alternative determination of these derived ${ }^{129} \mathrm{Xe}^{*} /{ }^{128} \mathrm{Xe} *$ and trapped ${ }^{129} \mathrm{Xe} /{ }^{132} \mathrm{Xe}$ ratios for Shallowater, we also examined the data in plots of ${ }^{128} \mathrm{Xe} /{ }^{129} \mathrm{Xe}$ versus ${ }^{132} \mathrm{Xe} /{ }^{129} \mathrm{Xe}$. Weighed Williams data fits of these plots gave for samples $1-02+2-02$ and $1-03+2-03,{ }^{129} \mathrm{Xe}^{* / 128} \mathrm{Xe}^{*}=0.4711 \pm 0.0083$ and $0.3981 \pm 0.0093$, respectively, and trapped ${ }^{129} \mathrm{Xe} /{ }^{132} \mathrm{Xe}=0.94 \pm 0.05$ and $0.93 \pm 0.09$, respectively. These values are virtually identical to those derived from the plot shown in Fig. 6B. The derived trapped ${ }^{129} \mathrm{Xe} /{ }^{132} \mathrm{Xe}$ ratios for Shallowater are slightly lower than, but within uncertainty of the terrestrial atmosphere value of 0.98 .

Adopting the ${ }^{129} \mathrm{Xe}^{* / 128} \mathrm{Xe}^{*}$ ratios obtained from the slopes of the isochron plots for Caddo Co and Shallowater, we use the radioactive decay equation, N/No $=\exp \{-\lambda \mathrm{t}\}$, to calculate the I-Xe age of Caddo relative to Shallowater. We set $\mathrm{N} / \mathrm{No}=0.8211 \pm 0.0189$. This value is the ratio of the isochron slopes for Caddo and Shallowater, and the uncertainty includes the analytical uncertainty in each slope. Using a mean life of $22.66 \mathrm{Myr}$ for ${ }^{129} \mathrm{I}$ (Brazzle et al., 1999), we calculate an ${ }^{129} \mathrm{I}-{ }^{129} \mathrm{Xe}$ age for Caddo County that is $4.44 \pm 0.10 \mathrm{Myr}$ younger than that for Shallowater. Using the absolute I-Xe age for Shallowater of 4,562.3 \pm 0.4 Myr recently reported by Gilmour et al. (2004), we obtain an absolute I-Xe retention age for Caddo County of 4,557.9 $\pm 0.1 \mathrm{Myr}$, where the age uncertainty does not include the uncertainty in the absolute I-Xe age of Shallowater.

\section{EET8333 and Udei Station}

Compared to Caddo County, total concentrations of ${ }^{132} \mathrm{Xe}$ in EET8333 and Udei Station are similar; concentrations of ${ }^{128} \mathrm{Xe}^{*}$ (and I) are somewhat higher; and concentrations of ${ }^{129} \mathrm{Xe}^{*}$ are somewhat smaller. However, iodine in the EET8333 and Udei Station samples analyzed is contained in two distinct phases that release $\mathrm{Xe}$ at different temperatures. Much of the ${ }^{129} \mathrm{Xe}^{*}$ in the lower temperature phase has been lost by diffusion, and this iodine may be associated with sulfide. The first three extractions of EET8333 and Udei Station released, in addition to adsorbed terrestrial Xe, $80 \%$ and 
$35 \%$, respectively, of their total ${ }^{128} \mathrm{Xe}$, compared to only $2.5 \%$ for Caddo. For EET8333 and Udei Station the ${ }^{129} \mathrm{Xe} /{ }^{132} \mathrm{Xe}$ ratios reach their maxima at $\sim 1250^{\circ} \mathrm{C}$ and $\sim 1075^{\circ} \mathrm{C}$, respectively, whereas the ${ }^{128} \mathrm{Xe} /{ }^{132} \mathrm{Xe}$ ratios are greatest at temperatures $<1000^{\circ} \mathrm{C}$. (For Caddo both ratios maximize at $\sim 1330^{\circ} \mathrm{C}$.) The ${ }^{129} \mathrm{Xe} /{ }^{132} \mathrm{Xe}$ versus ${ }^{128} \mathrm{Xe} /{ }^{132} \mathrm{Xe}$ isochron plots for these two samples (not presented) scatter much more highly than the isochron plot for Caddo, and no linear trends are indicated. Therefore, we calculate the ${ }^{129} \mathrm{I}^{129} \mathrm{Xe}$ age (relative to an I-Xe age of $4562.3 \mathrm{Myr}$ for Shallowater) for each individual temperature extraction and plot these ages against cumulative release of ${ }^{128} \mathrm{Xe}^{*}$ (Fig 7). Such age spectra are analogous to the Ar-Ar age spectra presented earlier. Because the first extraction of EET8333 alone released $63 \%$ of the ${ }^{128} \mathrm{Xe}$, Fig. 7a plots only data for the last $40 \%$ of the ${ }^{128} \mathrm{Xe}$ release. (The I-Xe age for the first extraction is partially displayed in the first $3 \%$ of the ${ }^{128} \mathrm{Xe}$ release.)

The higher temperature extractions of EET8333 and Udei Station gave measured ${ }^{129} \mathrm{Xe} /{ }^{132} \mathrm{Xe}$ ratios of $\sim 2.5-4$, considerable smaller than those for Caddo. To obtain the radiogenic ${ }^{129} \mathrm{Xe}^{*}$ and ${ }^{128} \mathrm{Xe}^{*}$ concentrations for each extraction, we assume trapped ${ }^{129} \mathrm{Xe} /{ }^{132} \mathrm{Xe}=1.00 \pm 0.02$, which is similar to the value on Earth and in primitive chondrites. We also assume trapped ${ }^{128} \mathrm{Xe} /{ }^{132} \mathrm{Xe}$ ratios near the terrestrial value $(0.072 \pm 0.002)$ for the first few extractions and the chondritic value $(0.082 \pm 0.002)$ for higher temperature extractions. The uncertainties arbitrarily assigned to these trapped compositions were statistically combined with the isotopic measurement uncertainties of the ${ }^{129} \mathrm{Xe}^{* / 128} \mathrm{Xe}^{*}$ ratios in each IAB sample in order to derive an uncertainty in each calculated I-Xe age. For all extractions of EET8333 and most extractions of Udei Station, applied corrections for cosmogenic Xe change the ${ }^{129} \mathrm{Xe} /{ }^{132} \mathrm{Xe}$ and ${ }^{128} \mathrm{Xe} /{ }^{132} \mathrm{Xe}$ ratios by no more than a few percent. As was the case with Caddo, most of the fission $\mathrm{Xe}$ is released at a temperatures of $\sim 700^{\circ} \mathrm{C}$. We applied small corrections for fission Xe to these low-temperature extractions.

The I-Xe ages (4557-4560 Myr) shown by the three highest temperature extractions of EET83333 are essentially identical to the I-Xe age for Caddo, whereas the oldest I-Xe age shown by Udei Station (4537 $\pm 3 \mathrm{Myr}$ ) is younger. At lower extraction temperatures, both meteorites give poorly defined plateau ages of 4460 Myr for EET83333 and 4400 Myr for Udei Station. These apparent plateaus ages may be artifacts produced by large diffusive losses of ${ }^{129} \mathrm{Xe}^{*}$ and our assumption of a particular trapped ${ }^{129} \mathrm{Xe} /{ }^{132} \mathrm{Xe}$ ratio.

For comparison, Fig. 7 also gives the I-Xe age spectrum for Caddo. Those extractions releasing $\sim 7-30 \%$ of the ${ }^{128} \mathrm{Xe}$ suggest ages that are older by $\sim 1$ Myr compared to ages for $>30 \%$ of the ${ }^{128} \mathrm{Xe}$ release. The reason for these older ages is not clear. They may indicate the presence of a small excess ${ }^{129} \mathrm{Xe}^{*}$ component mobilized during silicate metamorphism.

\section{Xe and Ar Diffusion}

The rate of release of Ar and Xe during stepwise temperature heating in the laboratory contains information about Ar and Xe diffusion in these IAB samples, which may help decipher the thermal history of these meteorites. We calculated the diffusivities, $\mathrm{D} / \mathrm{a}^{2}$, from the rate of release of ${ }^{128} \mathrm{Xe}$ as a function of extraction temperature and plotted these against inverse temperature in Arrhenius plots (Fechtig \& Kalbitzer, 1966; Bogard \& Hirsch, 1980). Because the data indicate that iodine was located in two sites of quite different Xe diffusivities, we calculated $\mathrm{D} / \mathrm{a}^{2}$ values considering only the ${ }^{128} \mathrm{Xe}$ released above intermediate temperatures. These data probably represent a single indigeneous I phase. 
Figure 8a shows the Xe Arrhenius data for $>1000^{\circ} \mathrm{C}$ extractions of Caddo (releasing $94 \%$ of the total

${ }^{128} \mathrm{Xe}$ ) and $>850^{\circ} \mathrm{C}$ extractions of EET 8333 (releasing $14 \%$ of the total ${ }^{128} \mathrm{Xe}$ ). The Arrhenius trend for EET8333 is reasonably well defined by seven extractions over the temperature range $1000-1300^{\circ} \mathrm{C}$.

The trend for the Caddo data is defined by four extractions releasing $78 \%$ of the ${ }^{128} \mathrm{Xe}$ and is consistent with two lower temperature extractions releasing an additional $13 \%$ of the ${ }^{128} \mathrm{Xe}$. The two highest temperature extractions of Caddo (open symbols, $>1300^{\circ} \mathrm{C}$ ) released only $2 \%$ of the ${ }^{128} \mathrm{Xe}$. They fall off the Arrhenius trend, probably because the silicate had melted and the Xe released was that dissolved in the melt. The activation energies for ${ }^{128} \mathrm{Xe}$ diffusion calculated from these data are $\sim 82 \mathrm{kcal} / \mathrm{mole}$ for EET8333 and $\sim 189 \mathrm{kcal} / \mathrm{mole}$ for Caddo. The lower energy for EET8333 compared to Caddo is consistent with an apparent ${ }^{129} \mathrm{Xe}^{*}$ diffusion loss profile in the EET8333 ${ }^{128} \mathrm{Xe}$ release (Fig. 8a).

We also evaluated Arrhenius diffusion plots for ${ }^{39} \mathrm{Ar}$ in the IAB silicate samples analyzed for Ar-Ar ages. The rates of Ar release as a function of temperature is complex for all of these samples and suggest multiple K-bearing diffusion domains that significantly overlap in their Ar release. For each sample we estimated the temperature range for the major ${ }^{39} \mathrm{Ar}$ release peak, which typically degassed over $\sim 600-950{ }^{\circ} \mathrm{C}$ and released $59 \%$ to $71 \%$ of the total ${ }^{39} \mathrm{Ar}$. From these data we calculated D/a ${ }^{2}$ values, and Arrhenius plots for four of these samples are given in Fig. 8b. Although some differences exist in the slopes of these Arrhenius trends, each of them give a D/a value of $1 \times 10^{-5} \mathrm{~cm}^{-1}$ at a similar temperature of $\sim 850^{\circ} \mathrm{C}(1000 / \mathrm{T}=0.89)$. In contrast, a $\mathrm{D} / \mathrm{a}^{2}$ value of $1 \times 10^{-5} \mathrm{~cm}^{-1}$ for ${ }^{128} \mathrm{Xe}$ diffusion occurs for much higher temperatures of $\sim 1230^{\circ} \mathrm{C}$ (Fig. 8a). This illustrates the significant difference in ease of diffusion between $\mathrm{Ar}$ and $\mathrm{Xe}$ in these meteorites. The activation energies for ${ }^{39} \mathrm{Ar}$ diffusion calculated from the slopes of the four data sets plotted in Fig. $8 \mathrm{~b}$ range from $\sim 54 \mathrm{kcal} / \mathrm{mole}$ to $\sim 80$ $\mathrm{kcal} / \mathrm{mole}$. Turner et al. (1978) reported activation energies for Ar diffusion in several chondrites across the broad range of $22-70 \mathrm{kcal} / \mathrm{mole}$. Bogard et al. (1990) reported Ar activation energies of 18-54 $\mathrm{kcal} /$ mole in several mesosiderites .

\section{Previous Work:}

\section{IAB Age Comparisons}

Several radiometric ages for IAB meteorites have been reported. Analyses of ${ }^{187} \mathrm{Re} /{ }^{187} \mathrm{Os}$ in metal from three IABs plotted on a $4.61 \mathrm{Gyr}$ isochron defined by other types of iron meteorites (Shen et al., 1996). Burnett and Wasserburg (1967) reported imprecise ${ }^{87} \mathrm{Rb}-{ }^{87} \mathrm{Sr}$ ages of 4.4-4.8 Gyr for Toluca and Four Corners, and Bogard et al. (1968) reported classical K-Ar ages of $4.55 \pm 0.1$ and $4.50 \pm 0.1$ Gyr for the same samples. Niemeyer (1979a) reported ${ }^{129} \mathrm{I}^{129} \mathrm{Xe}$ ages for silicate and troilite from five IAB meteorites, which when normalized to an age of 4562.3 Myr for the Bjurböle standard used, give ages of $~ 4546-4574$ Myr. Podosek (1970) reported an I-Xe age of 4558.6 $\pm 0.7 \mathrm{Myr}$ for Campo del Cielo, when normalized to this Bjurböle age. These ages are consistent with IAB formation very early in solar system history. However, some other IAB age determinations give younger values. For Caddo County silicate Stewart et al. (1996) reported a ${ }^{147} \mathrm{Sm} /{ }^{143} \mathrm{Nd}$ age of $4.53 \pm 0.02 \mathrm{Gyr}$; and Liu et al (2002) reported a Sm-Nd age of $4.50 \pm 0.04 \mathrm{Gyr}$ and a $\mathrm{Rb}-\mathrm{Sr}$ age of $4.52 \pm 0.03 \mathrm{Gyr}$. Liu et al. (2003) reported a Rb-Sr isochron age of $4.54 \pm 0.08 \mathrm{Gyr}$ for Campo del Cielo. Niemeyer (1979b) reported ${ }^{39} \mathrm{Ar}-{ }^{40} \mathrm{Ar}$ ages of 4.48-4.57 Gyr for silicate from five IAB meteorites. When these ages are corrected for changes to the age of the irradiation monitor used, they become $4.43-4.52$ Gyr. Takeda et al. (2000) reported an ${ }^{39} \mathrm{Ar}-{ }^{40} \mathrm{Ar}$ age for Caddo County that ranged over 4.516-4.54 Gyr, and Benedix et al. (1998) reported 
${ }^{39} \mathrm{Ar}-{ }^{40} \mathrm{Ar}$ ages of $4.529 \pm 0.013 \mathrm{Gyr}$ and $\sim 4.51 \mathrm{Gyr}$ for the winonaites Pontlyfni and Winona, respectively. In addition, Herpfer et al. (1994) used Ni concentration profiles in metal to determine cooling rates of $\sim 25-70^{\circ} \mathrm{C} / \mathrm{Myr}$ for eight IAB meteorites, with one additional meteorite suggesting a rate of $\sim 200^{\circ} \mathrm{C} / \mathrm{Myr}$.

Some radiometric age determinations previously reported for IAB meteorites and the new data reported here are summarized in Table 2. Uncertainties reported for these Ar-Ar and I-Xe ages are from the original work and do not consider uncertainties in the absolute age of the irradiation monitor used. The preferred Ar-Ar age of the St Severin chondrite, used as an age standard in the investigation by Niemeyer (1979b), has subsequently changed, which lowers the originally reported Ar-Ar ages by 1.1\%. (Corrected ages are given in Table 2.) Further, different Ar-Ar ages reported for St. Severin show some variation, probably because the Ar-Ar age is not constant with extraction temperature, and the "plateau age" obtained for St. Severin depends upon the temperature interval over which the Ar ages are averaged. (See Appendix 3 in Bogard et al., 2000, for a discussion of this point.) Thus, considering uncertainties in these older Ar-Ar ages, it is not clear whether they are definitely younger than the I-Xe ages.

The I-Xe ages for IABs reported by Niemeyer (1979a) and Podosek (1970) were calculated relative to the Bjurböle L4 chondrite, which was in common use as an age standard at that time. Further, the Bjurböle data reported by Niemeyer (1979a) were not well-behaved and contribute an additional uncertainty to his IAB ages beyond those uncertainties given for each IAB age. More recently, the preferred I-Xe age standard has been the Shallowater aubrite. As discussed earlier, Brazzle et al. (1999) list the absolute I-Xe ages for both Bjurböle and Shallowater as $4566 \pm 2$ Myr. More recently the I-Xe age for Shallowater has been reported as $4562.3 \pm 0.4 \mathrm{Myr}$ (Gilmour et al., 2004). In calculating the I-Xe ages reported here, we assume absolute I-Xe ages of both Bjurböle and Shallowater to be 4562.3 Myr. Note that the uncertainties in these monitor ages are not included in the I-Xe ages for meteorites listed in Table 2. In addition, we applied a correction to the earlier reported IXe ages to account for a change in the adopted half-life of ${ }^{129} \mathrm{I}$. Only in the case of Niemeyer's data for Pitts troilite and Mundrabilla troilite did this correction exceed 0.1 Myr.

\section{Comparison of Radiometric Ages:}

The precise Ar-Ar ages of $\sim 4.507 \pm 0.010$ Gyr reported here for Caddo samples \#5 and 027 are identical within uncertainties to our previous analysis of a gabbroic clast in Caddo (Takeda et al., 2000). This previous sample \#2 gave an average Ar-Ar plateau age of $4.520 \pm 0.006 \mathrm{Gyr}$ for $84 \%$ of the ${ }^{39} \mathrm{Ar}$ release, an isochron age of $4.515 \pm 0.003 \mathrm{Gyr}\left(\mathrm{R}^{2}=0.999999\right.$; corrected for cosmogenic $\left.{ }^{36} \mathrm{Ar}\right)$ and $a{ }^{40} \mathrm{Ar} /{ }^{36} \mathrm{Ar}$ intercept of $28 \pm 88$. The Caddo age of $4.51 \mathrm{Gyr}$ is also identical within uncertainties to corrected Ar-Ar ages of $4.516 \pm 0.03 \mathrm{Gyr}$ reported by Niemeyer $(1979 \mathrm{~b})$ for three other IAB silicates (Mundrabilla, Woodbine and etched Pitts; Table 2). The reported Sm-Nd ages (4.53 $\pm 0.02 \mathrm{Gyr}$ and $4.50 \pm 0.04 \mathrm{Gyr})$ and the reported $\mathrm{Rb}-\mathrm{Sr}$ age $(4.52 \pm 0.03 \mathrm{Gyr})$ for Caddo are also identical within uncertainties to the Caddo Ar-Ar age. Our Ar-Ar age for EET8333 and Udei Station and Niemeyer's ages for Copiapo and Landes are distinctly younger at 4.3-4.45 Gyr. Takeda et al. (2000) concluded that the gabbroic clast in Caddo formed as a result of strong metamorphism within the parent body. From their Sm-Nd study, Stewart et al. (1996) concluded that Caddo probably formed at depths $>2 \mathrm{~km}$ within the first $\sim 30 \mathrm{Myr}$ of solar system history, but they did not rule out later formation at more 
shallow depths. Woodbine, Mundrabilla, and Pitts probably experienced a similar thermal history as Caddo.

The ${ }^{129} \mathrm{I}-{ }^{129} \mathrm{Xe}$ age reported here for Caddo County (4557.9 $\left.\pm 0.1 \mathrm{Myr}\right)$ and the oldest ages for EET83333 ( 4557-4560 Myr) are essentially identical to the I-Xe age for Campo del Cielo (4558.6 $\pm 0.7 \mathrm{Myr}$ ), but slightly younger than the range of corrected I-Xe ages of $\sim 4560-4565 \mathrm{Myr}$ for silicates in IABs reported by Niemeyer (1979a). The younger I-Xe ages for Udei Station and Pitts troilite may reflect some ${ }^{129} \mathrm{Xe}$ diffusion loss, and ${ }^{128} \mathrm{Xe}$ in both samples was released at lower temperatures compared to the other samples. Niemeyer (1979a) discussed analytical difficulties experienced with some of his analyses, and he listed only the ages for Woodbine, Mundrabilla silicate, and possibly Landes as being "well-defined". The ages for these three samples vary over 4560-4566 Myr. The observation that Caddo and Campo have similar and precise I-Xe ages obtained using different age standards indicates that the particular age standard used is not a factor.

Reported I-Xe ages for a variety of meteorite types show a wide range of $\sim 4570 \mathrm{Myr}$ to $\sim 4551$ Myr (Gilmour et al., 2004; Brazzle et al., 1999). However, Pb-Pb isochron ages, coupled with ${ }^{26} \mathrm{Al}-$

${ }^{26} \mathrm{Mg}$ systematics, indicate that the first materials to condense in the solar system, refractory CAIs, did so $4567 \mathrm{Myr}$ ago, and that chondrules condensed 2-3 Myr later (Amelin et al., 2002). Further, a time period of a few Myr may have been required to accrete and substantially melt any sizeable asteroidal body (Bennett and McSween 1996). Pb-Pb ages of chondrites and differentiated meteorites essentially are all $\leq 4560 \mathrm{Myr}$ (Carlson \& Lugmair, 2000; Göpel et al., 1994). Thus, it seems unlikely that the IAB parent could have formed and partially melted and differentiated prior to $\sim 4562 \mathrm{Myr}$ ago.

We considered three explanations for those oldest I-Xe ages of IAB meteorites. First is the possibility that the I-Xe system in some IAB meteorites was not reset during early parent body metamorphism, but it was reset in other IABs. This might explain the apparent range of $\sim 7 \mathrm{Myr}$ in the more precisely determined I-Xe ages, but it does not explain those ages too old to be realistic. Secondly, the I-Xe age determinations given by Niemeyer (1979a) may be in error. We prefer this explanation for those ages older than $\sim 4565 \mathrm{Myr}$, but it may also be the case for the younger ages reported by Niemeyer. A third explanation considered is that there exists a significant uncertainty in the absolute IXe age calibration. This explanation, however, would not account for the apparent range in I-Xe ages of IABs reported by Neimeyer (1979). It is unlikely that any significant bias exists in the I-Xe chronometer calibration, and certainly nothing that could make the I-Xe ages of IABs as young as ages derived by the other radiometric systems.

\section{Thermal History of IAB Meteorites}

Because the isotopic chronology of IABs suggests a complex formation, we will compare these ages against the two-stage formation model proposed by Benedix et al. (2000) for the IAB parent body. This model permits, in principle, more than one age resetting event. In this model the IAB parent underwent strong metamorphism and partial differentiation, which produced metallic, sulfide-rich, and silicate melts. The $\sim 4.56$ Gyr I-Xe ages determined for several IABs suggest that accretion and melting of the IAB parent occurred within a few Myr after initial formation of solid objects in the solar system. While the body was near its maximum temperature, it experienced a catastrophic impact, causing breakup, which was followed by reassembly and incomplete mixing of components. Thus, different 
parts of the IAB body may have experienced quite different maximum temperatures. Benedix et al. (2000) suggest that metallic melts may have reached $\sim 1400^{\circ} \mathrm{C}$, silicate partial melts reached at least $\sim 1050^{\circ} \mathrm{C}$, residues of partial silicate melts reached up to $\sim 1250 \mathrm{C}$, but less metamorphosed chondritic silicates reached not more than $\sim 950^{\circ} \mathrm{C}$. Mixing of these and other components during impact reassembly might be expected to produce relatively rapid cooling of some components down to an equilibrium temperature, followed by slower cooling, depending on the burial depth after reassembly. Winonaites may represent near surface silicate regions of the parent body, and some winonaites are only moderately metamorphosed and not mixed with metal (Benedix et al., 1998; 2000). Scott (2004) and others have argued that breakup and reassembly of asteroids in the early solar system may have been a relatively common process.

Observations we made of Caddo PTSs may not be wholly consistent with the above model. Mineralogical evidence deduced from the Caddo samples (Takeda et al., 2000) suggests that the reassembly and metamorphic events could be a local impact disturbance rather than a planet-wide phenomenon. Further, the presence of the winonaite-like area within a few $\mathrm{cm}$ of the metallic area and andesitic partial melt area in Caddo County (Takeda et al., 2000) is not explained by the Benedix et al. model.

\section{Closure Temperatures:}

Direct estimates of the cooling rates of several IAB meteorites have been made from measurements of the Ni concentration profiles in adjacent metal phases having very different $\mathrm{Ni}$ concentrations (Herpfer et al., 1994). Ni cooling rates for 7 meteorites ranged over $25-70{ }^{\circ} \mathrm{C} / \mathrm{Myr}$, with uncertainties of $\pm 5-20^{\circ} \mathrm{C} / \mathrm{Myr}$, and an eighth meteorite suggested a cooling rate of $\sim 200{ }^{\circ} \mathrm{C} / \mathrm{Myr}$. Although Caddo Co. was not included in this study, all but two IAB meteorites studied have either a KAr age or an Ar-Ar age reported in Table 2.

Can a thermal model of IAB meteorites be identified that reconciles the mixture of old and young radiometric ages, metal cooling rates, and the complex metamorphic and impact history suggested for the IAB parent body by Benedix et al. (2000)? In a system with relatively slow metal cooling rates, Ni concentration differences between metal phases begin forming at $>600^{\circ} \mathrm{C}$, and $\mathrm{Ni}$ diffusion would effectively continue to temperatures of $\angle 400^{\circ} \mathrm{C}$. The rate at which Ni diffuses depends somewhat on composition of the metal (e.g., Narayan and Goldstein, 1985). For comparison to the Ar and Xe closure temperatures (calculated below), we will assume that Ni diffusion closes in the range of $\sim 350-450^{\circ} \mathrm{C}$.

Different radiometric chronometers can have very different temperatures at which the system closes to diffusion, and in the case of relatively slow cooling of the parent body, these chronometers may give different ages. We used the diffusion data for ${ }^{39} \mathrm{Ar}$ and ${ }^{128} \mathrm{Xe}$ discussed above and the method given by Dodson (1973) to calculate effective closure temperatures for the K-Ar and I-Xe chronometers. These calculations require, in addition to data on diffusivity at a given temperature, an estimate of the cooling rate. We assumed cooling rates of $10^{\circ} \mathrm{C} / \mathrm{Myr}$ and $100^{\circ} \mathrm{C} / \mathrm{Myr}$, which bracket the cooling rates determined from Ni profiles in metal. Using measured $\mathrm{D} / \mathrm{a}^{2}$, this range in cooling rates, and the range in measured ${ }^{39} \mathrm{Ar}$ activation energies of $55-80 \mathrm{kcal} / \mathrm{mole}$ (Fig. 8b) we calculate closure temperatures for the $\mathrm{K}$-Ar chronometer of $\sim 575-700 \mathrm{~K}$. This range of K-Ar closure temperatures is slightly higher than those determined for ordinary chondrites ( 375-675 K; Turner et al., 1978). Caddo \#2 and EET8333 
indicate ${ }^{128} \mathrm{Xe}$ activation energies that differ by more than a factor of two (Fig. 8a), which is probably the result of different mineralogical sitting for I in the two samples. We estimate closure temperatures for the I-Xe system of $\sim 1100 \mathrm{~K}$ for Caddo and $\sim 800 \mathrm{~K}$ for EET8333. From the Xe data reported by Podosek (1970) we estimate a similar closure temperature for Campo del Cielo to that for EET8333. Because Niemeyer (1979a) did not report Xe isotopic data for the IABs he studied, we cannot estimate $\mathrm{D} / \mathrm{a}^{2}$ and closure temperatures from his I-Xe data. Niemeyer (1979a) noted that his IAB I-Xe ages roughly correlated with $\mathrm{Ni}$ concentration of the metal. Using the spread in I-Xe ages and the Ni cooling rates, Herpfer et al. (1994) estimated the closure temperature for I-Xe at $\sim 1140 \mathrm{~K}$.

Little relevant data exist for the closure temperatures of the $\mathrm{Sm}-\mathrm{Nd}$ and $\mathrm{Rb}-\mathrm{Sr}$ chronometers. Cherniak and Watson (1994) reported an extensive study of Sr diffusion in plagioclase of different compositions. The $\mathrm{Sr}$ activation energies were similar at $\sim 64 \mathrm{kcal} / \mathrm{mole}$ but the diffusivity, $\mathrm{D}$, decreased with increasing An of the plagioclase. We used their diffusion data, an estimated grain diameter for Caddo plagioclase of $1 \mathrm{~mm}$ (Stewart et al., 1996), and the equations of Dodson (1973) to estimate a closure temperature of $600-700^{\circ} \mathrm{C}$ for the $\mathrm{Rb}-\mathrm{Sr}$ chronometer in plagioclase. The $\mathrm{Sm}-\mathrm{Nd}$ system is considered to be more resistant to resetting than is Rb-Sr, and Stewart et al (1996) considered that $\mathrm{Nd}$ diffusion in feldspar might be an order of magnitude slower than $\mathrm{Sr}$ diffusion. Because these radiometric ages for Caddo Co. are based on mineral isochrons, where the various minerals likely have different $\mathrm{Sr}$ and rare earth diffusion characteristics, the concept of a single closure temperature probably does apply. In an artificial heating study on a lunar basalt, Nyquist et al (1991) demonstrated that Rb$\mathrm{Sr}$ and $\mathrm{Sm}-\mathrm{Nd}$ mineral isochrons could be rotated and partially reset, while retaining some of their original linearity.

\section{Thermal Models and Age Comparison:}

Figure 9 compares the radiometric ages of IABs against some simple thermal models based on the metal cooling rates. We assume that cooling began at a temperature of $1200^{\circ} \mathrm{C}(1473 \mathrm{~K})$. This temperature may be too low for much of the metal and too high for some silicates (Benedix et al., 2000). The rate of cooling at any given temperature is assumed to be proportional to the temperature interval between that given temperature and the ambient temperature of the parent body surface (Wood, 1979). We calculated cooling curves for two ambient surface temperatures, 292K and 173K (Ghosh and $\mathrm{McSween}, 1998$ ). Cooling curves using these two assumptions differ noticeably only for temperatures $<500 \mathrm{~K}$, and thus our discussion is insensitive to the choice of parent body surface temperature. We assume that cooling of the IABs began at two different times, 4.56 Gyr ago and 4.53 Gyr ago. For each assumed initial time and temperature we show two cooling curves. One curve represents a cooling rate of $25^{\circ} \mathrm{C} / \mathrm{Myr}$ and the other $70^{\circ} \mathrm{C} / \mathrm{Myr}$, the range of values obtained from Ni profiles in metal (Herpfer et al., 1994). In constructing these cooling curves we assume the Ni cooling rates are defined at a temperature of $500^{\circ} \mathrm{C}$, but the positions of these curves change very little if we assume slightly higher or lower temperatures. Similarly, the positions of the cooling curves are relatively insensitive to starting temperature. If we raise or lower the $1200^{\circ} \mathrm{C}$ starting temperature by $200^{\circ} \mathrm{C}$, the positions of the cooling curves at $700 \mathrm{~K}$ change by an amount equivalent to only a few million years.

Various IAB ages obtained by Ar-Ar, I-Xe, Rb-Sr, and Sm-Nd are plotted in Fig. 9, using their closure temperatures estimated above. The range of closure temperatures for $\mathrm{K}-\mathrm{Ar}, \sim 575-700 \mathrm{~K}$, is shown as a rectangle, whereas the closure temperatures for $\mathrm{Rb}-\mathrm{Sr}$ and $\mathrm{Sm}-\mathrm{Nd}$ are more uncertain and 
are simply plotted as points. (We arbitrarily assume that the Sm-Nd chronometer closes at a temperature $100^{\circ} \mathrm{C}$ higher than that for $\mathrm{Rb}-\mathrm{Sr}$.) Analytical uncertainties on the $\mathrm{Rb}-\mathrm{Sr}$ and $\mathrm{Sm}-\mathrm{Nd}$ ages (2-sigma) and on the Ar-Ar age for the Pontlyfni winonaite (1-sigma) are indicated. The I-Xe age for Caddo is plotted as two separate triangles using the closure temperatures estimated from Caddo Co. $\left(\sim 1100^{\circ} \mathrm{C}\right)$ and EET83333 $\left(\sim 800^{\circ} \mathrm{C}\right)$. The range in temperature used for closure of Ni diffusion in metal $\left(350-500^{\circ} \mathrm{C}\right)$ has no associated age. We have sized and plotted the rectangular fields for $\mathrm{Ni}$ diffusion in Fig. 9 to be consistent with the experimental range in $\mathrm{Ni}$ cooling rates $\left(25-70^{\circ} \mathrm{C} / \mathrm{Myr}\right)$ for the two cases of cooling beginning at ages of 4.56 and $4.53 \mathrm{Gyr}$. The model cooling curves are required to pass through some portion of the rectangular field defined by the Ni data in Fig. 9.

The 4558 Myr I-Xe ages for Caddo County and Campo del Cielo (Table 2) are consistent with cooling that began $4.56 \mathrm{Gyr}$ ago, if the I-Xe closure temperature is $\sim 1100^{\circ} \mathrm{C}$. If the I-Xe closure temperature is $800^{\circ} \mathrm{C}$, these ages could be too old by up to $\sim 10 \mathrm{Myr}$, depending on the cooling rate. The older I-Xe ages (Table 2) reported by Niemeyer (1979a) are obviously inconsistent with cooling that began 4.560 Gyr ago, independent of the I-Xe closure temperature. In contrast to the I-Xe ages, the $\mathrm{Rb}-\mathrm{Sr}$ and $\mathrm{Sm}-\mathrm{Nd}$ ages of Caddo are too young to be consistent with the $4.56 \mathrm{Gyr}$ model cooling curves, unless the actual uncertainties in these ages are greater than those reported. All Ar-Ar ages of IAB meteorites and the winonaites also are too young to be consistent with the $4.56 \mathrm{Gyr}$ model cooling curve, as previously pointed out by Herpfer et al. (1994) for data by Niemeyer (1979b). If we consider the possibility that in the formation model of Benedix et al. (2000), impact disruption, mixing, and reassembly of the IAB parent body occurred $4.53 \mathrm{Gyr}$ ago, then many of these radiometric ages are in good agreement with these cooling curves (Fig. 9). For cooling that initiates at $4.53 \mathrm{Gyr}$, four IABs (Caddo, Woodbine, Pitts, and Mundrabilla) and Winona plot within the pair of cooling curves defined by the metal. Given their larger uncertainties, the ${ }^{40} \mathrm{~K}-{ }^{40} \mathrm{Ar}$ ages of Toluca and Four Corners (not plotted) could also be consistent with this younger set of cooling curves. Decreasing the starting temperature for cooling to $1325 \mathrm{~K}$, approximately the temperature at which silicate begins to melt, does not significantly change this relationship. The winonaite Pontlyfni may plot at an older age because its silicate was not mixed with hot metal and it may have cooled faster than IABs nearer the parent body surface. Several additional IABs (Copiapo, Landes, EET83333, Campo del Cielo, and Udei Station) show significantly younger Ar-Ar ages of $~ 4.3-4.45 \mathrm{Gyr}$ and are not consistent with this cooling model. Yet, four of these meteorites give I-Xe ages of $\geq 4.56$ Gyr (Table 2). These younger Ar-Ar ages probably indicate later impact heating events on the parent body or loss of ${ }^{40} \mathrm{Ar}$ due to terrestrial weathering.

In addition to the investigations discussed above, two other studies also addressed IAB cooling rates. In measuring the composition of Re and Os in coexisting schreibersite and metal for two IABs, Shen et al (1996) concluded that the Re-Os chronometer remained open for a significant period of time and suggested that the metal cooled at a rate of $\sim 1^{\circ} \mathrm{C} / \mathrm{Myr}$ (see Fig. 9). Although such a slow cooling rate might apply to initial cooling of high-temperature metal, and prior to break-up and reassembly of the parent body, it could not have persisted for a significant period of time and be consistent with the other IAB data. In another study, fission track measurements of apatite in Copiapo gave a cooling rate of $\sim 1^{\circ} \mathrm{C} / \mathrm{Myr}$ (Benkheiri et al., 1979) which was later changed to $\sim 8^{\circ} \mathrm{C} / \mathrm{Myr}$ (P. Pellas, pers.

comm..quoted in Herpfer et al., 1994). Because fission tracks in apatite begin to be retained at $\sim 360 \mathrm{~K}$ (Pellas et al., 1997) and because the Ni cooling rate for Copiapo was determined to be $30 \pm 10{ }^{\circ} \mathrm{C} / \mathrm{Myr}$ 
(Herpfer et al, 1994), this fission track cooling rate defines a point on the Copiapo metal cooling curve. Thus, within the uncertainties associated with the metal cooling rate and fission track data for Copiapo, the plotted Copiapo fission track datum implies an age of $\sim 4.485$ Gyr (Fig. 9) if Ni cooling began 4.53 Gyr ago. However, the Ar-Ar age of Capiapo is inconsistent with both the track datum and its Ni cooling rate, suggesting ${ }^{40} \mathrm{Ar}$ diffusion loss.

For the I-Xe ages of IABs to be consistent with cooling that initiated $4.53 \mathrm{Gyr}$ ago, however, all I-Xe ages would have to be reduced by $\sim 30$ Myr. Such a bias in all absolute I-Xe ages of meteorites is very unlikely. This consideration suggests that the I-Xe chronometer was not strongly affected by the thermal event that reset the K-Ar, Sm-Nd and Rb-Sr ages. Whitby et al (2002) observed similar results in chondrules from an enstatite chondrite, whose Ar-Ar and $\mathrm{Rb}-\mathrm{Sr}$ ages were strongly disturbed, but whose I-Xe ages were all $\sim 4566 \mathrm{Myr}$. If the closure temperature of I-Xe is $\sim 1100^{\circ} \mathrm{C}$, then it may have been possible to heat IAB silicate close to melting $\sim 4.53 \mathrm{Gyr}$ ago without resetting the I-Xe, particularly if following impact mixing these meteorites were deeply buried in an environment that retarded $\mathrm{Xe}$ diffusive loss. However, if the closure temperature of I-Xe in these samples was only $\sim 800^{\circ} \mathrm{C}$, then the $\mathrm{I}$-Xe ages appear discordant with the $\mathrm{Sm}-\mathrm{Nd}$ and $\mathrm{Rb}-\mathrm{Sr}$ ages. Another possibility is that the I-Xe chronometer was only partially reset by a heating event $4.53 \mathrm{Gyr}$ ago. In possible support of this is the observation by Benedix et al. (2000) that the two IABs with the oldest I-Xe silicate ages, Woodbine and Pitts, were quenched after phase mixing and the observation by Herpfer et al (1994) that these two meteorites cooled relatively quickly through $\sim 500^{\circ} \mathrm{C}$.

It is also conceivable that the younger $\mathrm{K}-\mathrm{Ar}$ ages of IABs are the result of a systematic bias in this chronometer. Based on comparisons of $\mathrm{Pb}-\mathrm{Pb}$ and $\mathrm{Ar}-\mathrm{Ar}$ ages determined in the same samples, Renne (2000) and Min et al. (2000) have suggested that the ${ }^{40} \mathrm{~K}$ decay coefficients in common use are incorrect, and that K-Ar ages of all old dated meteorites should be increased by $~ 47 \mathrm{Myr}$. However, an increase of this magnitude would make some of the IAB Ar-Ar ages older than that allowed by the 4.56 Gyr model cooling curves. Trieloff et al. (2001) also argued from acapulcoite and winonaite data that any $\mathrm{K}-\mathrm{Ar}$ age bias must be less than $47 \mathrm{Myr}$. From a comparison of $\mathrm{Ar}-\mathrm{Ar}$ and $\mathrm{Pb}-\mathrm{Pb}$ ages of a suite of H-chondrites, Trieloff et al. (2003) suggested a K-Ar age bias of $~ 30 \mathrm{Myr}$ for those meteorites with ArAr ages of 4.5 Gyr. A bias of $230 \mathrm{Myr}$ in K-Ar ages of IABs would bring several of their Ar-Ar ages into agreement with Ni cooling curves that initiated 4.56 Gyr ago (Fig. 9). But, with such a correction the K-Ar ages would be older than the Sm-Nd and $\mathrm{Rb}-\mathrm{Sr}$ ages of Caddo, and would require these latter ages to be at the upper limits or more of their reported 2-sigma uncertainties. Another conceivable explanation of the discrepancy in ages may be that the IAB parent body had a thermal history even more complex than that offered by Benedix et al. (2000). The body may have been partially melted, impact disrupted, and mixed and reassembled $\sim 4.56 \mathrm{Gyr}$ ago. The body may then have experienced $\sim 4.52 \mathrm{Gyr}$ ago one or more milder impact events that did not heat silicate close to the initial melting point, but was sufficient to reset radiometric chronometers other than I-Xe. This may explain some petrologic characteristics of Caddo County noted above. Clearly we do not have a consistent and satisfactory explanation of the early thermal history of IAB meteorites.

\section{CONCLUSIONS}

Studies of several samples of Caddo County have revealed the following. A coarse-grained 
silicate inclusion, rich in diopside and albite but containing less than 2\% of Opx and olivine, was found in a new slab of the IAB Caddo County iron. Discovery of this pure andesitic material supports the previous proposal (Takeda et al., 2000) that melt segregated from chondritic source materials is unlike eucrites and has a composition high in $\mathrm{Si}, \mathrm{Na}, \mathrm{Al}$ and $\mathrm{Ca}$. The presence of microtextures recorded in a few large pyroxene and albite crystals supports grain coarsening as a mechanism of partial melt segregation. This is the first reported andesitic asteroidal material. The presence of the large Di biases the bulk composition, but discussion of the REE abundance estimated from the previous modal abundance is still supported. The textures, mineralogy and REE data suggest that the andesitic materials in Caddo were not formed by Earth-like mechanisms, but formed by inhomogeneous segregation of partial melts from chondritic source materials.

Radiometric ages determined for IAB meteorites do not suggest a simple history. Several I-Xe ages fall in the range of 4558-4666 Myr, but the more reliable among these are $\sim 4558 \mathrm{Myr}$. Some I-Xe ages appear unrealistically old and may or may not indicate a real variation in I-Xe ages and thermal history among different IAB meteorites. (The oldest known solid objects in the solar system are only $\sim 4567 \mathrm{Myr}$ in age (Amelin et al., 2002), and at least a few Myr probably were required for asteroidsized objects to accrete and partially melt.) In contrast to the old I-Xe ages, Ar-Ar ages for several $\mathrm{IABs}$ and $\mathrm{Sm}-\mathrm{Nd}$ and $\mathrm{Rb}-\mathrm{Sr}$ isochron ages for Caddo County are $\geq 30 \mathrm{Myr}$ younger than the likely formation time of the IAB parent body.

Because the determined chronology of IAB meteorites appears complex, we have considered the IAB formation model of Benedix et al. (2000), which may permit, in principle, different events to be recorded in the ages. In this model the IAB parent body largely melted, then underwent collisional breakup, followed by partial mixing of phases and reassembly. Even with this model however, the age data as a whole do not support a consistent thermal history for IABs, and the exact time of metamorphism and partial differentiation of material in Caddo and other IABs is not yet defined.

From measurements of Ni concentration profiles in metal of seven IABs, Herpfer et al. (1994) determined that these meteorites cooled through a temperature range of $\sim 400-500^{\circ} \mathrm{C}$ at rates of 25 $70^{\circ} \mathrm{C} / \mathrm{Myr}$. If these cooling rates initiated $\sim 4.56 \mathrm{Gyr}$ ago, they are inconsistent with all Ar-Ar ages determined for IABs and two winonaites and with $\mathrm{Sm}-\mathrm{Nd}$ and $\mathrm{Rb}-\mathrm{Sr}$ isochron ages determined for Caddo County. Several of these Ar-Ar ages would be consistent with cooling that initiated $4.53 \mathrm{Gyr}$ ago, as would the Sm-Nd and $\mathrm{Rb}-\mathrm{Sr}$ age for Caddo. However, breakup and reassembly of the IAB parent at $\sim 4.53$ Gyr would be inconsistent with the I-Xe ages, unless the I-Xe chronometer is much more resistant to resetting than are these other chronometers. Another possibility is that a second, milder reheating event 4.52 Gyr ago reset only the Ar-Ar ages and that the Sm-Nd and Rb-Sr ages for Caddo are actually older than their reported error limits would indicate. Still another possibility is that there exists a bias in the decay parameters for ${ }^{40} \mathrm{~K}$ and that all Ar-Ar ages for most meteorites are actually $\sim 30$ Myr older (Renne, 2000; Trieloff et al., 2003). This explanation, however, would not account for the younger $\mathrm{Sm}-\mathrm{Nd}$ and $\mathrm{Rb}-\mathrm{Sr}$ ages for Caddo County.

\section{Acknowledgements}

We thank Y. Liu for preparing the plagioclase separate of Caddo EH; C-Y Shih for help in preparing the analyzed sample of Kindle County; and T. Ishii and M. Otsuki for their help in modal analysis. We thank the Univ. of Tokyo for furnishing Caddo samples EH and 027; and the U.S. 
Natural History Museum for furnishing the samples of EET8333, Udei Station, Kendall County, and Campo del Cielo. We thank M. Trieloff, J. Gilmour, C. Hohenberg, O. Pradivtseva, and T. Swindle for constructive comments on the paper. All isotopic analyses were supported by NASA's Cosmochemistry Program.

\section{REFERENCES}

Amelin Y., Krot A. N., Hutcheon I. D., and Ulyanov A. A. (2002) Lead isotopic ages of chondrules and calcium-aluminum-rich inclusions. Science 297, 1678-1683.

Benedix G. K., McCoy T. J., Keil K., Bogard D. D., and Garrison D. H. (1998) A petrologic and isotopic study of winonaites: Evidence for early parent body partial melting, brecciation, and metamorphism. Geochim. Cosmochim. Acta 62, 2535-2553.

Benedix G. K., McCoy T. J., Keil K., and Love S.G. (2000) A petrologic study of the IAB iron meteorites: Constraints on the formation of the IAB-Winonaite parent body. Meteor. Planet. Sci. 35, 1127-1141.

Benkheiri Y., Pellas P., and Storzer D. (1979) The cooling histories of Copiapo and Landes (1A) irons. Icarus 40, 497-501.

Bild R. (1977) Silicate inclusions in group IAB irons and a relation to the anomalous stones Winona and Mt. Morris (Wis). Geochim. Cosmochim. Acta. 41, 1439-1456.

Bogard D.D. and Hirsch W.C. (1980) ${ }^{40} \mathrm{Ar}^{39} \mathrm{Ar}$ dating, Ar diffusion properties, and cooling rate determinations of severely shocked chondrites. Geochim. Cosmochim. Acta. 44, 1667-1682.

Bogard D. D., Burnett D. S., Eberhardt P., and Wasserburg G. J. (1968) ${ }^{40} \mathrm{Ar}-{ }^{40} \mathrm{~K}$ ages of silicate inclusions in iron meteorites. Earth Planet. Sci. Lett. 3, 275-283.

Bogard D. D., Funkhouser J. G., Schaeffer O. A., and Zahringer J. (1971) Noble gas abundances in lunar material: Cosmic ray spallation products and radiation ages from the Sea of Tranquility and the Ocean of Storms. J. Geophys. Res. 76, 2757-2779.

Bogard D. D., Garrison D. H., Norman M., Scott E. R. D., and Keil K. (1995) ${ }^{39} \mathrm{Ar}-{ }^{40} \mathrm{Ar}$ age and petrology of Chico: Large-scale impact melting on the L chondrite parent body. Geochim. Cosmochim. Acta. 59, 1383-1400.

Bogard D. D., Garrison D. H., and McCoy T. J. (2000) Chronology and petrology of silicates from IIE iron meteorites: Evidence of a complex parent body evolution. Geochim. Cosmochim. Acta 64, 21332154

Brazzle R. H., Pravdivtseva O. V., Meshik A. P., and Hohenberg C. M. (1999) Verification and interpretation of the I-Xe chronometer. Geochim. Cosmochim. Acta 63, 739-760.

Busfield A., Gilmour J. D., Whitby J. A., and Turner G. (2004) Iodine-xenon analysis of ordinary chondrite halide: Implications for early solar system water. Geochim. Cosmochim. Acta 68, 195202.

Cherniak D. J. and Watson E. B. (1994) A study of strontium diffusion in plagioclase using Rutherford backscattering spectroscopy. Geochim. Cosmochim. Acta 58, 5179-5190.

Choi B-G., Ouyang X., and Wasson J. T. (1995) Classification and origin of IAB and IIICD iron meteorites. Geochim. Cosmochim. Acta 59, 593-612.

Clayton R. N. and Mayeda T. K. (1996) Oxygen isotope studies of achondrites. Geochim. Cosmochim. Acta 60, 1999-2018.

Dodson M. H. (1973) Closure temperature in cooling geochronological and petrological systems. Contrib. Mineral. Petrol. 40, 259-274.

Fechtig H. and Kalbitzer S. (1966) The diffusioin of argon in potassium-bearing solids. In Potassium Argon Dating (eds. O. Schaeffer and J. Zähringer), Springer Verlag, 68-107.

Ghosh A. and McSween H.Y. (1998) A thermal model for the differentiation of asteroid 4 Vesta, based 
on radiogenic heating. Icarus 134, 187-206.

Gilmour J. D., Whitby J. A., and Turner G. (2001) Negative correlation of iodine-129/iodine-127 and xenon-129/xenon-132: Product of closed system evolution or evidence of a mixed component. Meteor. Planet. Sci. 36, 1283-1286.

Gilmour J. D., Pravdivtseva O. V., Busfield A., and Hohenberg C. M. (2004) I-Xe and the chronology of the early solar system. Workshop on Chondrites and Protoplanetary Disk, Hawaii, Nov. 2004.

Herpfer M. A., Larimer J. W., and Goldstein J. I. (1994) A comparison of metallographic cooling rate methods used in iron meteorites. Geochim. Cosmochim. Acta 58, 1353-1365.

Hohenberg C. M. (1967) I-Xe dating of the Shallowater achondrite. Earth Planet. Sci. Lett. 3, 357-362.

Katcoff S. (1960) Fission product yields from neutron-induced fission. Nucleonics 18, 201-208.

Kracher A. (1985) the evolution of the partially differentiated planetesimals: Evidence from iron meteorite groups IAB and IIICD. J. Phys. Res. 90 (suppl.), C689-698.

Liu Y. Z., Nyquist L.E., Wiesmann H., Shih C-Y, and Takeda H. (2002) The age of plagioclasediopside inclusions in the Caddo County meteorite: $\mathrm{Rb}-\mathrm{Sr}$ and $\mathrm{Al}-\mathrm{Mg}$ isochrons. Meteor. Planet. Sci. 37, A89.

Liu Y. Z., Nyquist L.E., Wiesmann H., Shih S-Y, and Takeda H. (2002) Rb-Sr and Sm-Nd ages of plagioclase-diopside-rich material in Caddo County IAB iron meteorite. Lunar Planet. Sci. XXXIII, $\# 1389$.

Liu Y. Z., Nyquist L.E., Wiesmann H., Shih C-Y, Schwandt C., and Takeda H. (2003) Internal Rb-Sr age and initial $87 \mathrm{Sr} / 86 \mathrm{Sr}$ of a silicate inclusion from the Campo del Cielo iron meteorite. Lunar Planet. Sci. XXXIV, \#1983.

McCoy T. J., Keil K., Bogard D. D., Garrison D. H., Casanova I., Lindstrom M. M., Brearley A. J., Kelm K., Nichols R. H., and Hohenberg C. M. (1995) Origin and history of impact-melt rocks from the EL chondrite parent body. Geochim. Cosmochim. Acta 59, 161-176.

McSween H. Y., Jr. (2002) The Leonard Medal address: The rocks of Mars, from far and near. Meteorit. Planet. Sci., 37, 7-25.

Min K., Mundil R., Renne P. R., and Ludwig K. R. (2000) A test for systematic errors in ${ }^{40} \mathrm{Ar} /{ }^{39} \mathrm{Ar}$ geochronology through comparison with $\mathrm{U} / \mathrm{Pb}$ analysis of a 1.1-Ga rhyolite. Geochim. Cosmochim. Acta 64, 73-98.

Mittlefehldt D.W., McCoy T.J., Goodrich C.A., and Kracher A. (1998) Non-chondritic meteorites from asteroidal bodies. In Reviews in Mineralogy, Vol. 36, Planetary Materials (J.J. Papike, Ed.) Mineralogical Society of America, Washington, D.C.

Mori H. and Takeda H. (1981) Thermal and deformational histories of diogenites as inferred from their microtextures of orthopyroxene. Earth Planet. Sci. Lett. 53, 266-274.

Narayan C. and Goldstein J. I. (1985) A major revision of the iron meteorite cooling rates - An experimental study of the growth of Widmanstätten pattern. Geochim. Cosmochim. Acta 49, 397 410.

Nichols R. H., Hohenberg C. M., Kehm K., Kim Y., and Marti K. (1994) I-Xe studies of the Acapulco meteorite: Absolute I-Xe ages of individual phosphate grains and the Bjurböle standard. Geochim. Cosmochim. Acta 58, 2553-2561.

Niemeyer S. (1979a) I-Xe dating of silicate and troilite from IAB iron meteorites. Geochim. Cosmochim. Acta 43, 843-860.

Niemeyer S. (1979b) ${ }^{40} \mathrm{Ar}^{-39} \mathrm{Ar}$ dating of inclusions from IAB iron meteorites. Geochim. Cosmochim. Acta 43, 1829-1840.

Nyquist L. E., Bogard D. D., Garrison D. H., Bansal B. M., Wiesmann H., and Shih C-Y (1991) Thermal resetting of radiometric ages. I. Experimental investigations and II. Modeling and applications (abst.). Lunar Planet. Sci Conf. 22, 985-988.

Ozima M. and Podosek F. A. (1983) Noble gas geochemistry, Cambridge Univ. Press, p.20. 
Pellas P., Fiéni C., Trielof M., and Jessberger E. K. (1997) The cooling history of the Acapulco meteorite as recorded by the ${ }^{244} \mathrm{Pu}$ and ${ }^{40} \mathrm{Ar}-{ }^{39} \mathrm{Ar}$ chronometers. Geochim. Cosmochim. Acta $\mathbf{6} \mathbf{1}$, 3477-3502.

Pepin R. O. (1991) On the origin and early evolution of terrestrial planet atmospheres and meteoritic volatiles. Icarus 92, 2-79.

Podosek F. A. (1970) Dating of meteorites by the high-temperature release of iodine-correlated ${ }^{129} \mathrm{Xe}$. Geochim. Cosmochim. Acta 34, 341-366.

Pravdivtseva O. V., Amelin Y., Hohenberg C. M., and Meshik A. P. (2002) I-Xe dating: Comparison of $\mathrm{I}-\mathrm{Xe}$ and $\mathrm{Pb}-\mathrm{Pb}$ ages of Richardton chondrules and separated mineral phases. Lunar Planet. Sci. Conf. XXXIII, Abstract \#2041

Renne P. R. (2000) ${ }^{40} \mathrm{Ar} /{ }^{39} \mathrm{Ar}$ age of plagioclase from Acapulco meteorite and the problem of systematic errors in cosmochronology. Earth Planet. Sci. Lett. 175, 13-26.

Scott E. R. D. (2004) Meteoriic constraints on collisional rates in the primordial asteroid belt and its origin. Lunar Planet. Sci. 35, abst. \#1990

Shen J. J., Papanastassiou D. A., and Wasserburg G. J. (1996) Precise Re-Os determinations and systematics of iron meteorites. Geochim. Cosmochim. Acta 60, 2887-2900.

Stewart B., Papanastassiou D. A., and Wasserburg G. J. (1996) Sm-Nd systematics of a silicate inclusion in the Caddo IAB iron meteorite. Earth Planet. Sci. Lett. 143, 1-12.

Takeda H. Bogard D. D., Mittlefehldt D. W., and Garrison D. H. (2000) Mineralogy, petrology, chemistry and ${ }^{39} \mathrm{Ar}-{ }^{40} \mathrm{Ar}$ and exposure ages of the Caddo County IAB iron: Evidence for early partial melt segregation of a gabbro area rich in plagioclase-diopside. Geochim. Cosmochim. Acta 64, 13111327.

Takeda H., Hsu W. and Ogata H. (2001) Trace element chemnistry of minerals in chemically andesitic material in the Caddo County IAB iron meteorite. Antarct. Meteorites, XXVI, 135-137.

Trieloff M., Jessberger E. K., and Fiéni C. (2001) A comment on ${ }^{40} \mathrm{Ar} /{ }^{39} \mathrm{Ar}$ age of plagioclase from Acapulco meteorite and the problem of systematic errors in cosmochronology' by Paul R. Renne. Earth Planet. Sci. Lett. 190, 267-269.

Trieloff M., Jessberger E. K., Herrwerth I., Hopp J., Fléni C., Ghélis M., Bourot-Denise M., and Pellas P. (2003) Structure and thermal history of the H-chondrite parent asteroid revealed by thermochronometry. Nature 422, 502-506.

Turner G., Enright M. C., and Cadogan P. H. (1978) The early history of the chondrite parent bodies inferred from ${ }^{40} \mathrm{Ar}-{ }^{39} \mathrm{Ar}$ ages. Proc. $9^{\text {th }}$ Lunar Planet. Sci. Conf., 989-1025.

Wasson J. T. and Kallemeyn G. W. (2002) The IAB iron-meteorite complex: A group, five subgroups, numerous grouplets, closely related, mainly formed by crystal segregation in rapidly cooling melts. Geochim. Cosmochim. Acta 66, 2445-2473.

Whitby J. A., Gilmour J. D., Turner G., Prinz M., and Ash R. D., (2002) I-Xe dating of chondrules from the Qingzhen and Kota Kota enstatite chondrites. Geochim. Cosmochim. Acta 66, 347-359.

Williamson J. H. (1968) Least-squared fitting of a straight line. Can. J. Phys. 46, 1845-1847.

Wood J. A. (1979) Review of the metallographic cooling rates of meteorites and a new model for the planetesimals in which they formed. In Asteroids (ed. T. Gehrels) Univ. Arizona Press, 849-891. 


\section{FIGURE CAPTIONS}

Fig. 1. (PhotoCD 0691, No. 43) Photomicrograph (cross polarized light) of the entire silicate inclusion in Caddo County PTS \#EH. Width: $6.6 \mathrm{~mm}$. Note aligned inclusions in a large diopside crystal on the left.

Fig. 2. (PhotoCD 0691, No. 49) Photomicrograph (cross polarized light) of the entire silicate inclusion in Caddo PTS \#027. Width: $6.6 \mathrm{~mm}$. Note a twinned albite grain with oval-shaped mafic silicate inclusions and a large diopside crystal on the right.

Fig. 3. (PhotoCD 0691, No. 52) Photomicrograph of a close up view of a orthopyroxene crystal with linear arrays arranged along a curved plane. Cross polarized light. Width: $1.3 \mathrm{~mm}$

Figure 4. ${ }^{39} \mathrm{Ar}-{ }^{40} \mathrm{Ar}$ ages (rectangles, left scale) and $\mathrm{K} / \mathrm{Ca}$ ratios (stepped line, right scale) as a function of cumulative release of ${ }^{39} \mathrm{Ar}$ for stepwise temperature extractions of (a) Caddo County sample \#5, (b) Caddo County sample \#027, and (c) Caddo County sample \#EH. Relative uncertainties in individual ages are indicated by the width of the rectangles. Determined $\mathrm{K}$ and $\mathrm{Ca}$ concentrations are also given.

Figure 5. Ar-Ar age spectra for samples of (a) EET-83333, (b) Udei Station, (c) Campo del Cielo, and (d) Kendall County.

Figure 6. (Upper) Isochron plot of ${ }^{129} \mathrm{Xe} /{ }^{132} \mathrm{Xe}$ versus ${ }^{128} \mathrm{Xe} /{ }^{132} \mathrm{Xe}$ for Caddo County sample \#2. Eight higher-temperature extractions releasing $94 \%$ of the ${ }^{128} \mathrm{Xe}$ (circles) define the isochron slope. (Lower) Isochron plot of ${ }^{129} \mathrm{Xe} /{ }^{132} \mathrm{Xe}$ versus ${ }^{128} \mathrm{Xe} /{ }^{132} \mathrm{Xe}$ for higher temperature extractions of two Shallowater samples in irradiation \#02 (left scale) and two samples in irradiation \#03 (right scale). Note that the left and right ${ }^{129} \mathrm{Xe} /{ }^{132} \mathrm{Xe}$ scales are offset from each other.

Figure 7. ${ }^{129} \mathrm{I}-{ }^{129} \mathrm{Xe}$ age spectra for samples of (a) EET83333, (b) Udei Station, and (c) Caddo County \#2 as a function of ${ }^{128} \mathrm{Xe}$ cumulative release. Note the much more sensitive age scale for Caddo County.

Figure 8. Arrhenius diffusion plot (D/a ${ }^{2}$ versus reciprocal temperature in $\left.\mathrm{K}\right)$ for higher temperature extractions of ${ }^{128} \mathrm{Xe}$ from Caddo County \#2 and EET8333 (upper) and for stepwise temperature extractions of ${ }^{39} \mathrm{Ar}$ from four IAB samples (lower).

Figure 9. Comparison of possible thermal models (temperature versus time) with radiometric ages of IAB meteorites. Assuming initial temperatures of $1200^{\circ} \mathrm{C}$ (diamonds), Ni cooling rates for IAB metal (Herpfer et al., 1994) define a range of possible cooling curves (curved lines) for parent body metamorphism that began either $4.56 \mathrm{Gyr}$ or $4.53 \mathrm{Gyr}$ ago. The large, shaded rectangles define approximate temperatures and times for cessation of Ni diffusion for each cooling model. Determined Ar-Ar ages (circles) are plotted within their probable range of closure temperatures (large, open rectangle). I-Xe ages (triangles) assume two possible closure temperatures. Closure temperatures for $\mathrm{Sm}-\mathrm{Nd}$ and $\mathrm{Rb}-\mathrm{Sr}$ ages of Caddo (squares with errors) are only approximate. 
Table 1. Bulk Composition of Caddo County EH by Modal Mineralogy

\begin{tabular}{|c|c|c|c|c|c|}
\hline & $\mathrm{Ab}$ & Di & Opx & Olivine & Bulk \\
\hline Mod. vol\% & 45.6 & 53.2 & 1.2 & 0.02 & 100.02 \\
\hline $\mathrm{D}$ & 2.620 & 3.220 & 3.300 & 3.220 & \\
\hline $\begin{array}{l}\text { Mod } \\
\text { wt.frac }\end{array}$ & 0.405 & 0.581 & 0.013 & 0.000 & 1.000 \\
\hline $\mathrm{Na}_{2} \mathrm{O}$ & 9.76 & 0.67 & 0.06 & 0 & 4.35 \\
\hline $\mathrm{MgO}$ & 0.01 & 18.7 & 35 & 54.3 & 11.34 \\
\hline $\mathrm{Al}_{2} \mathrm{O}_{3}$ & 22.5 & 0.81 & 0.32 & 0.01 & 9.60 \\
\hline $\mathrm{SiO}_{2}$ & 64.1 & 54.4 & 57.4 & 41.8 & 58.37 \\
\hline $\mathrm{K}_{2} \mathrm{O}$ & 0.48 & 0 & 0 & 0 & 0.19 \\
\hline $\mathrm{CaO}$ & 3.1 & 21.6 & 1.22 & 0.02 & 13.83 \\
\hline $\mathrm{TiO}_{2}$ & 0.07 & 0.7 & 0.19 & 0.03 & 0.44 \\
\hline $\mathrm{Cr}_{2} \mathrm{O}_{3}$ & 0 & 0.87 & 0.41 & 0.06 & 0.51 \\
\hline $\mathrm{MnO}$ & 0 & 0.25 & 0.48 & 0.41 & 0.15 \\
\hline $\mathrm{FeO}$ & 0.09 & 1.74 & 4.85 & 4.05 & 1.11 \\
\hline TOTAL & 100.11 & 99.74 & 99.93 & 100.68 & 99.89 \\
\hline
\end{tabular}

\begin{tabular}{|l|l|l|l|l|l|}
\hline & & & & & \\
\hline & & & & & \\
\hline & & & & & \\
\hline & & & & & \\
\hline & & & & & \\
\hline & & & & & \\
\hline & & & & & \\
\hline & & & & & \\
\hline & & & & & \\
\hline & & & & & \\
\hline & & & & & \\
\hline & & & & & \\
\hline & & & & & \\
\hline & & & & & \\
\hline
\end{tabular}


Table 2. ${ }^{39} \mathrm{Ar}-{ }^{40} \mathrm{Ar}$ and ${ }^{129} \mathrm{I}-{ }^{129} \mathrm{Xe}$ ages of IAB meteorites.

\begin{tabular}{|l|l|l|l|}
\hline Meteorite & Ar-Ar, Gyr & I-Xe, Myr & Ref. \\
\hline Caddo Co. \#5 & $4.507 \pm 0.013$ & & a \\
\hline Caddo Co. \#027 & $4.506 \pm 0.010$ & & a \\
\hline Caddo Co. \#EH & $\begin{array}{l}\text { 4.489 } \\
\pm 0.023\end{array}$ & & a \\
\hline Caddo Co. \#2 & $4.520 \pm 0.006$ & $4557.9 \pm 0.1$ & b \\
\hline EET8333 & $4.32 \pm 0.02$ & $4557-4560$ & a \\
\hline Udei Station & $\sim 4.32$ & $\bullet 4537$ & a \\
\hline Campo del Cielo & $\sim 4.5$ & $4558.6 \pm 0.7$ & a, c \\
\hline Copiapo & $4.447 \pm 0.03$ & 4560.95 & d, e \\
& & \pm 0.66 & \\
\hline Woodbine & $4.516 \pm 0.03$ & $4565.92 \pm 0.3$ & d, e \\
\hline Mundrabilla silicate & $4.516 \pm 0.03$ & 4562.98 & d, e \\
& & \pm 0.59 & \\
\hline Mundrabilla troilite & & $4574.0 \pm 0.7$ & d, e \\
\hline Pitts (unetched0 & $4.487 \pm 0.03$ & 4562.73 & d, e \\
& & \pm 0.24 & \\
\hline Pitts (etched) & $4.516 \pm 0.03$ & 4564.78 & d, e \\
& & \pm 0.59 & \\
\hline Pitts troilite & & $4546.2 \pm 2.4$ & d, e \\
\hline Landes & $4.427 \pm 0.03$ & 4559.72 & d, e \\
& & \pm 0.62 & \\
\hline Kendall County & $\sim 4.4-4.5$ & & a \\
\hline Toluca (K-Ar) & $4.55 \pm 0.01$ & & f \\
\hline Four Corners (K-Ar) & $4.50 \pm 0.01$ & & f \\
\hline Pontlyfni * & $4.529 \pm 0.013$ & & g \\
\hline Winona * & $\sim 4.51$ & & \\
\hline
\end{tabular}

I-Xe ages are calculated assuming that the I-Xe age of Shallowater and Bjurböle are 4562.3 Myr. Samples marked with an* are winonaites. (a) this work; (b) Takeda et al., 2000; (c) Podosek, 1970; (d) Niemeyer, 1979b; (e) Niemeyer, 1979a; (f) Bogard et al., 1968; (g) Benedix et al., 1998. 
Figures 1-9 for MAPS paper by Bogard, Garrison \& Takeda

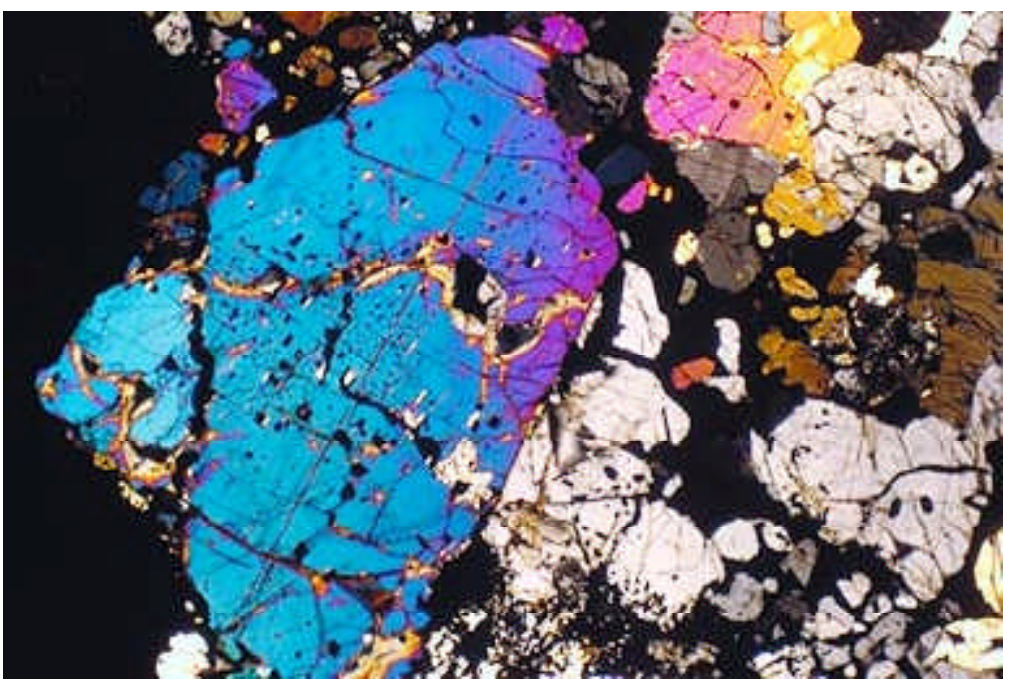

\section{Figure 1}

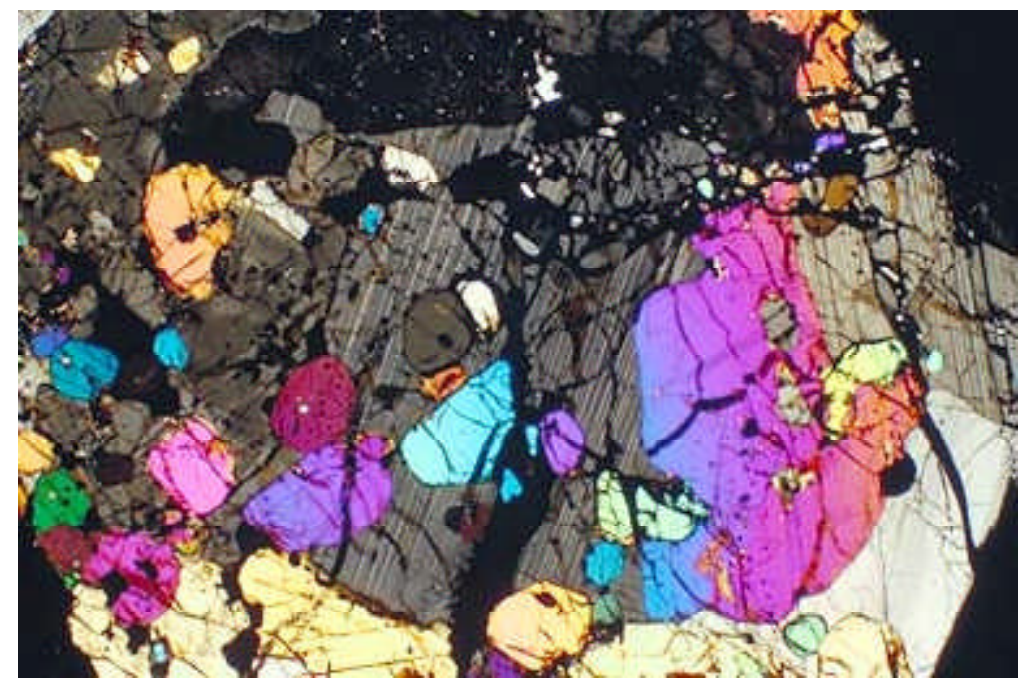

Figure 2 


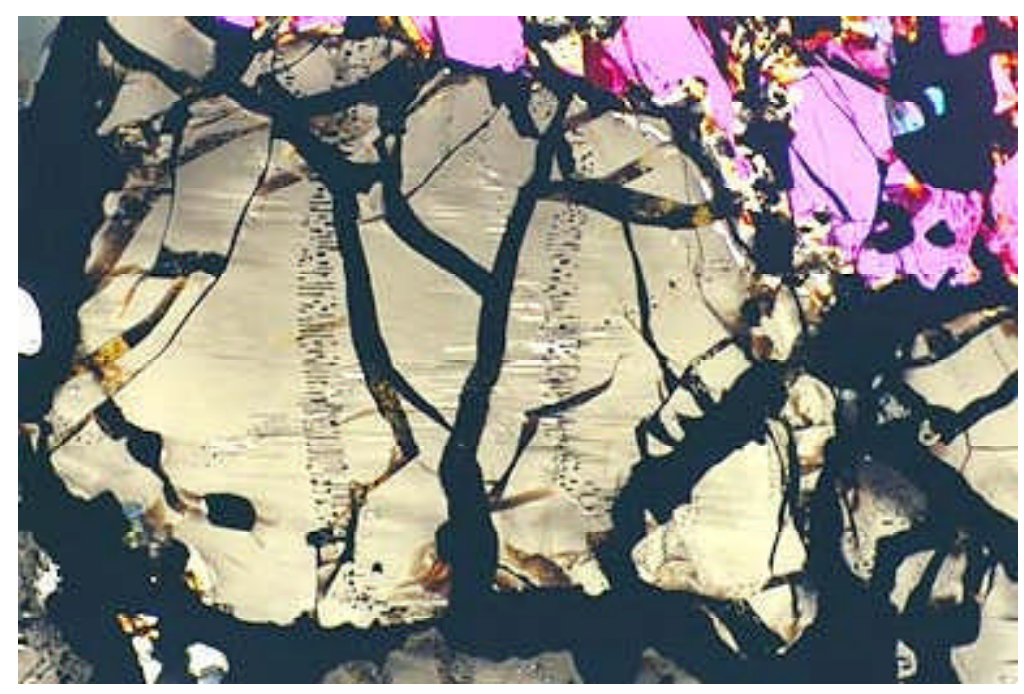

Figure 3 

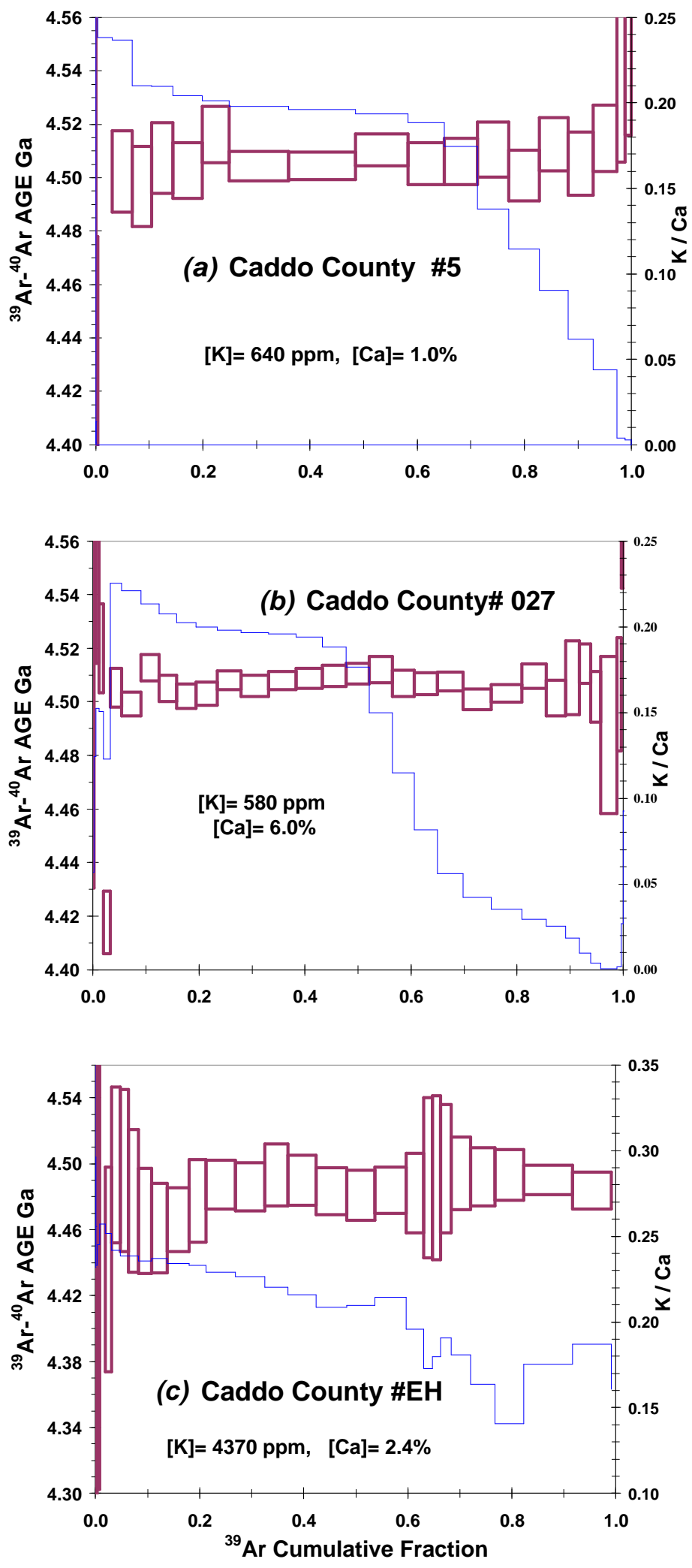

Figure 4 

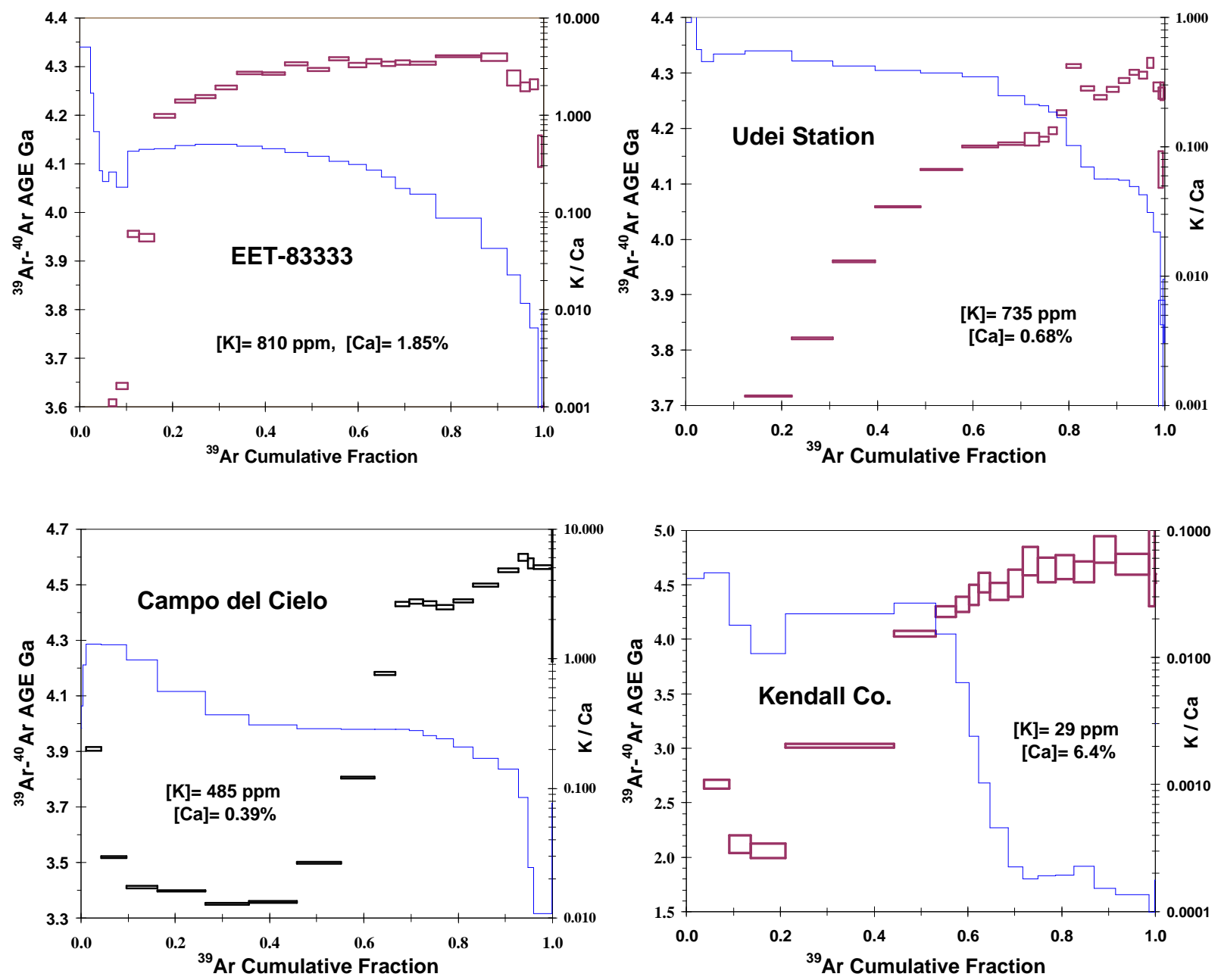

Figure 5 

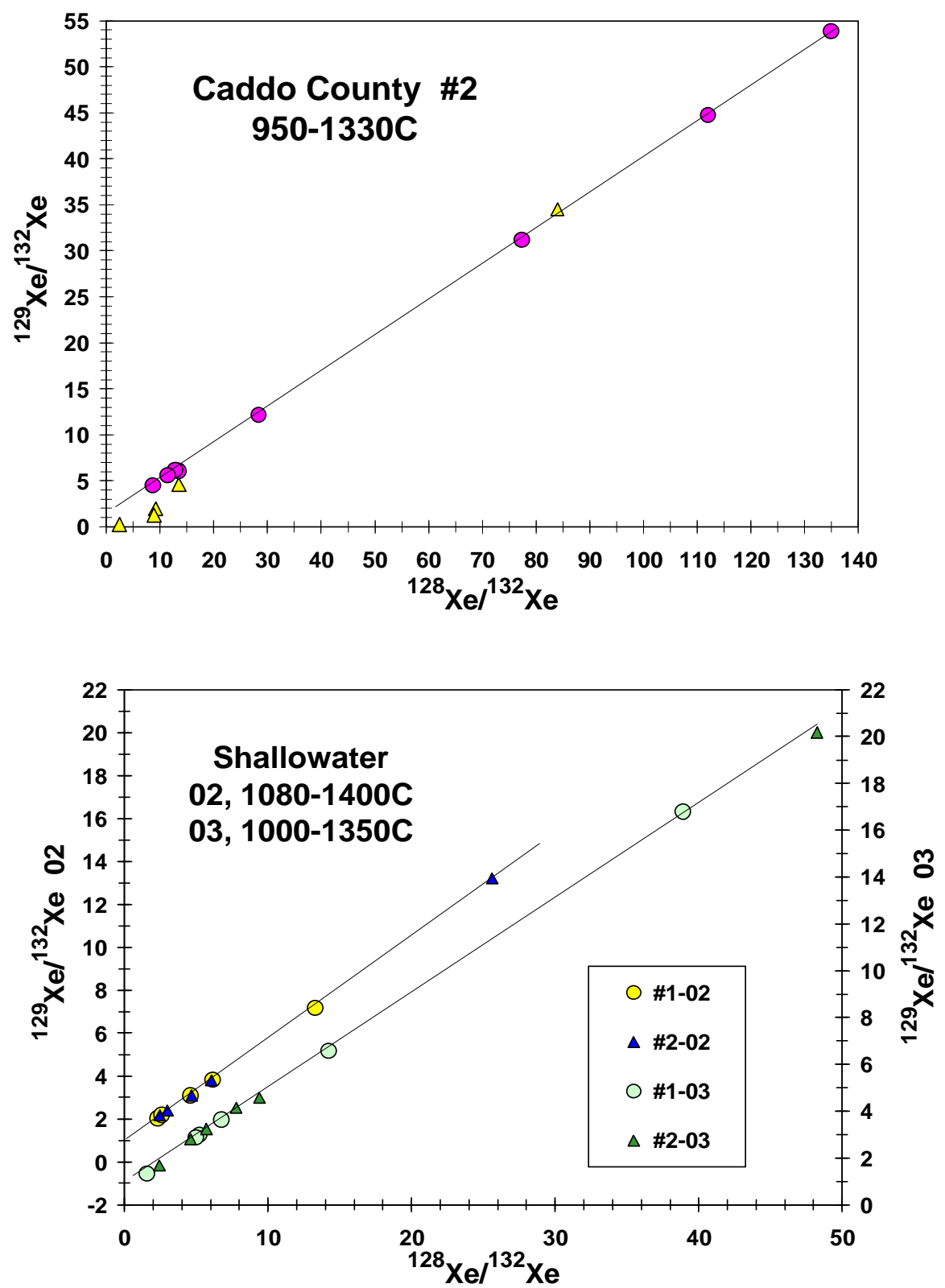

Figure 6 

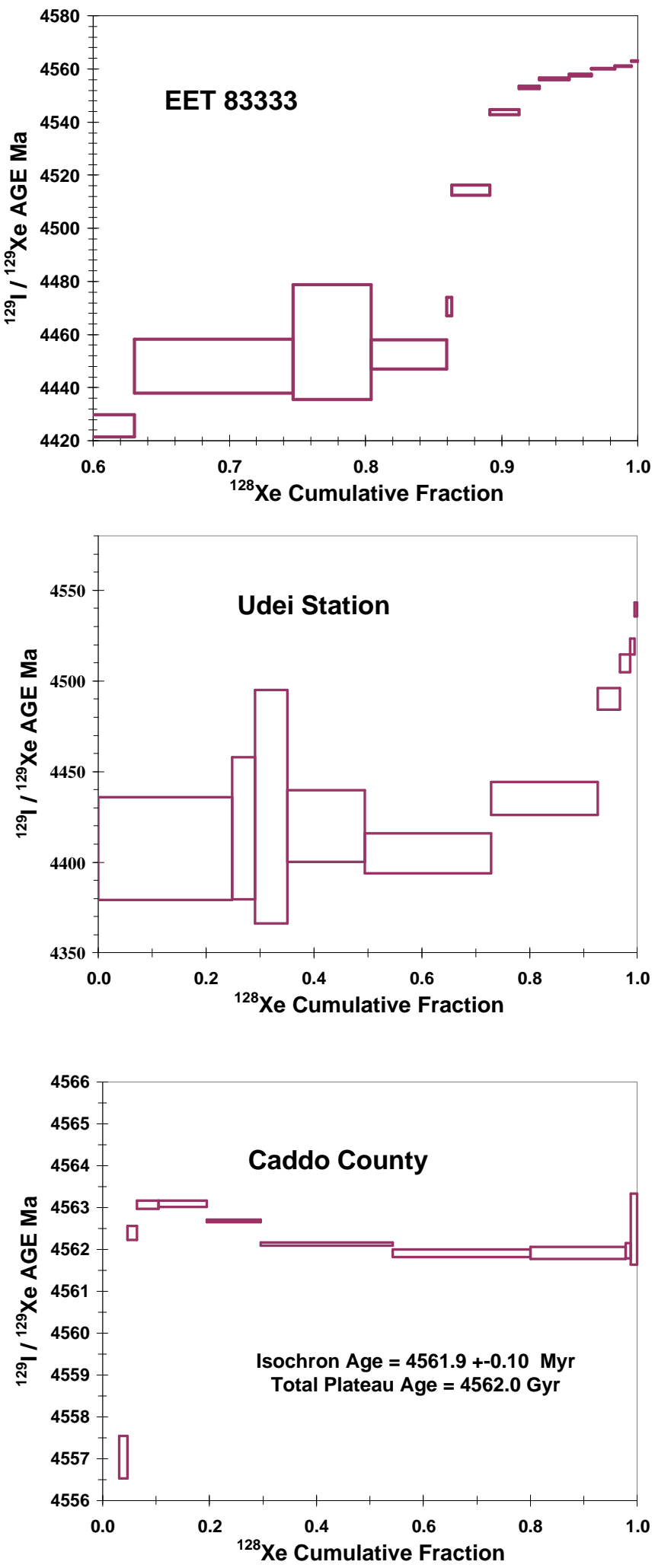

Figure 7 

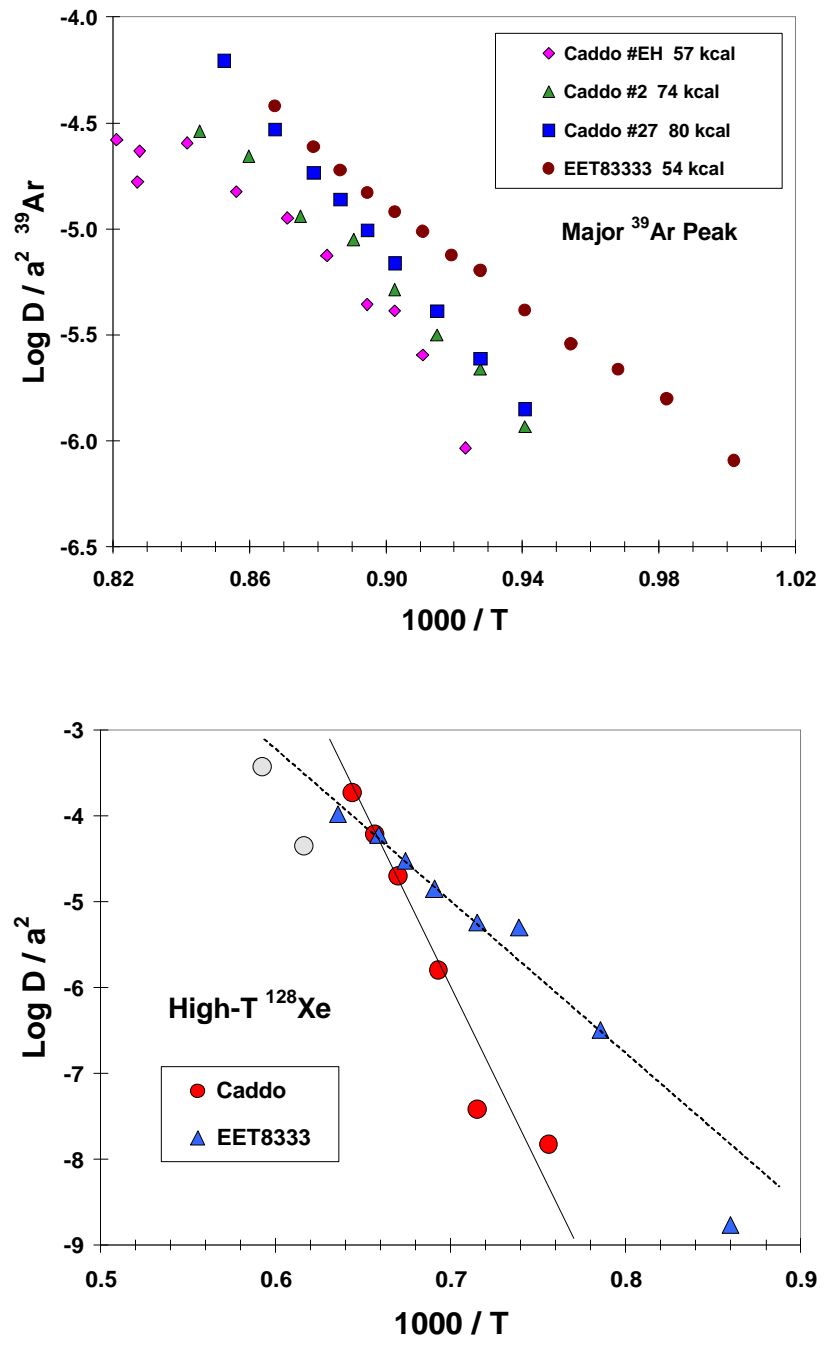

Figure 8 


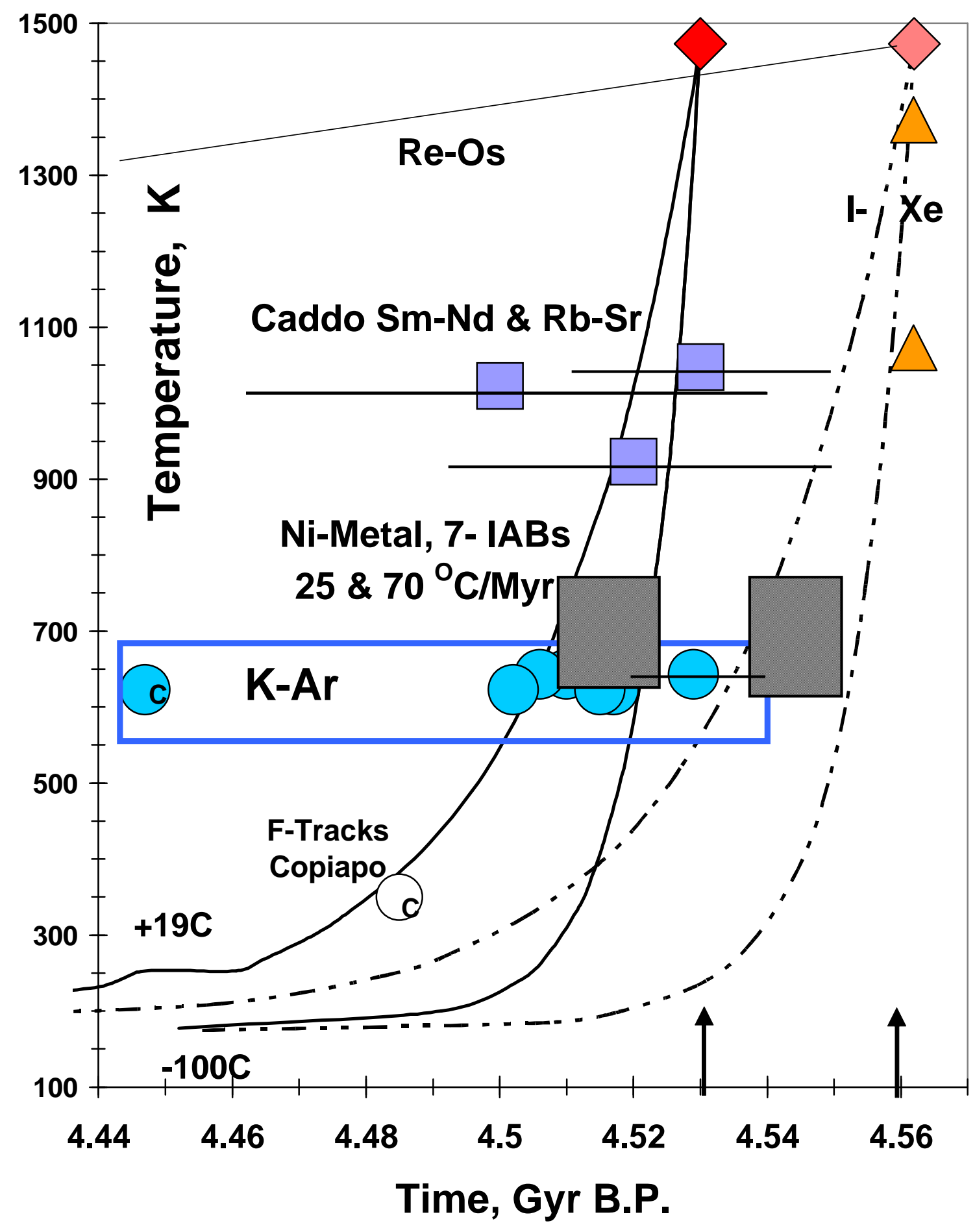

Figure 9 
